\title{
Analysis and Measurement of Bubble Dynamics and Associated Flow Field in Subcooled Nucleate Boiling Flows
}

\author{
Wen $\mathrm{Wu}$ \\ Barclay G. Jones \\ Department Nuclear, Plasma, and Radiological Engineering \\ University of Illinois at Urbana-Champaign
}

October 1, 2008

Urbana, Illinois 


\section{Acknowledgements}

The sponsorship of this research by the United States Department of Energy under Research Contract - DOE DE-FG07-04ID14601 (DOE NEER-Jones) is sincerely appreciated. Additionally, support from the Department of Nuclear, Plasma and Radiological Engineering of the University of Illinois at Urban-Champaign is gratefully acknowledged. Thanks also go to Dr. Ty A. Newell in the Department of Mechanical and Industrial Engineering, for his graciously sharing the test loop. 


\section{Table of Contents}

List of Symbols ...................................................................................................................... V

1 Introduction ............................................................................................................... 1

$2 \quad$ Project Accomplishments............................................................................... 3

$3 \quad$ Model Development........................................................................................... 4

3.1 Bubble Interaction (Coalescence) Probability ......................................................... 4

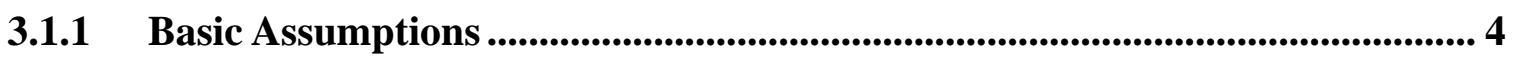

3.1.2 Probabilities of Two-Bubble Interaction ....................................................... 4

3.1.3 Probabilities of Multiple Interactions During Bubble Life Span...................... 7

3.1.4 Conditional Bubble Interaction Probability and Ergodic Principle................ 8

3.2 Mechanisms of Flow Boiling Heat Transfer.......................................................... 8

3.2.1 Forced Convection.................................................................................................... 8

3.2.2 Transient Conduction........................................................................................... 9

3.2.3 Microlayer Evaporation.................................................................................... 9

3.3 Energy Conservation Revisit ................................................................................ 10

3.4 Critical Heat Flux ........................................................................................ 10

3.5 Improved Heat Transfer Model Based on Bubble Motions................................11

$4 \quad$ Model Validation................................................................................................... 12

4.1 Active Nucleation Site Density ....................................................................... 12

4.2 Bubble Growth................................................................................................. 14

4.2.1 Measured Bubble Growth Rate .......................................................................... 14

4.3 Results on Bubble Departure and Bubble Lift-off ............................................. 14

4.3.1 Bubble Departure Radius ........................................................................... 14

4.3.2 Bubble Lift-Off Radius .............................................................................. 15

4.4 Model Prediction on Boiling Curves....................................................................... 17

4.4.1 Experimental Data Overview ................................................................................ 17

4.4.2 Comparison for R134a Data with Model Predictions at 400kPa .................... 18

4.4.3 Model Prediction at Higher Pressures .................................................................. 21

4.4.4 Comparison of Critical Heat Flux .......................................................................... 25

4.4.5 Comparison to Water Data in the Literature ....................................................... 26

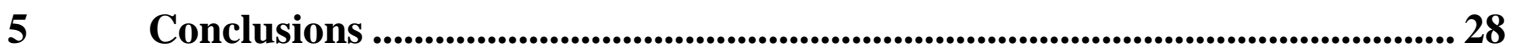

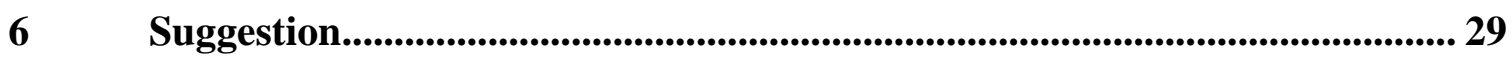

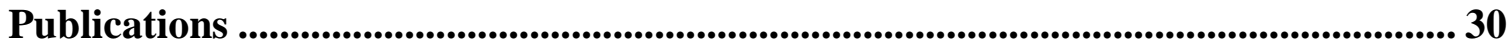

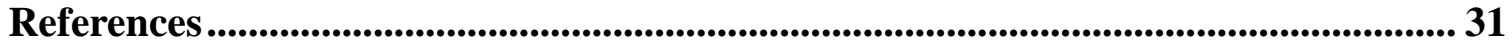




\section{List of Tables}

Table 1. Expressions for Different Heat Flux Components............................................. 10

Table 2. Test Numbers and Their Corresponding Conditions .......................................... 17

\section{List of Figures}

Fig. 1. Simplified Bubble Growth and Bubble Sliding Curves ........................................ 5

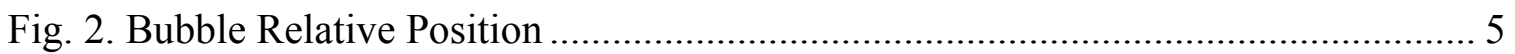

Fig. 3. Influence of Bubble during its Sliding ................................................................ 7

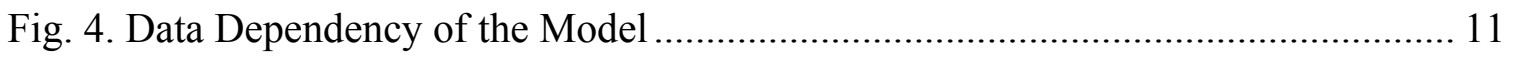

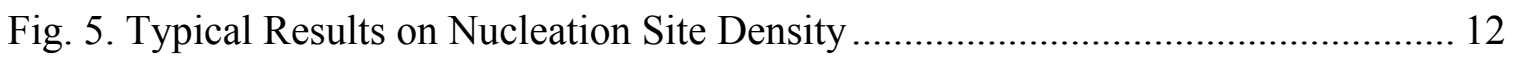

Fig. 6. Measured Nucleation Site Density ............................................................... 13

Fig. 7. Measured Bubble Growth at 400kPa................................................................. 14

Fig. 8. Bubble Departure Radius with Varying Liquid Velocity at Fixed $\Delta T_{\text {sat }} \ldots \ldots \ldots \ldots \ldots . . . .15$

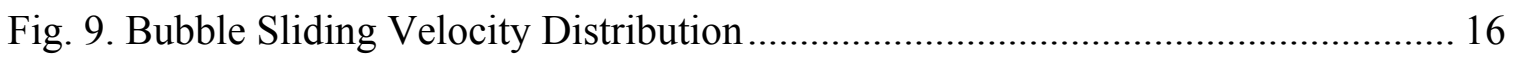

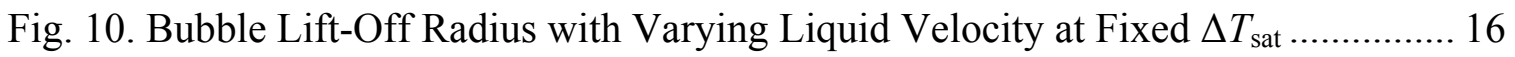

Fig. 11. Measured Boiling Curves under Different Experimental Conditions ................. 18

Fig. 12. Boiling Curve Comparison with R134a Data at 400kPa .................................. 19

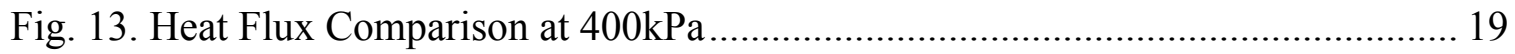

Fig. 14. Bubble Lift-off Radius Distribution at 400kPa ............................................ 20

Fig. 15. Fractional Contribution of Heat Flux at 400kPa ............................................. 21

Fig. 16. Boiling Curve Comparison with R134a Data at 600kPa ................................... 22

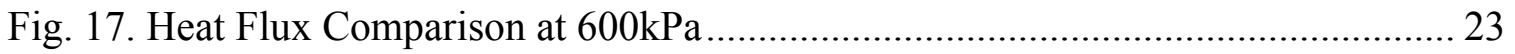

Fig. 18. Boiling Curve Comparison with R134a Data at 800kPa ………...................... 23

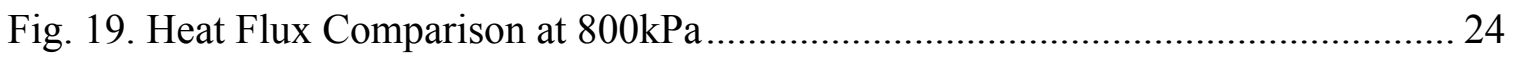

Fig. 20. Boiling Curve Comparison with R134a Data at 1000kPa................................. 24

Fig. 21. Heat Flux Comparison at 1000kPa............................................................. 25

Fig. 22. Critical Heat Flux Comparison with R134a Data.............................................. 26

Fig. 23. Boiling Curve Comparison with McAdams' [9] Data......................................... 27

Fig. 24. Boiling Curve Comparison with McAdams' [9] Data......................................... 27 


\section{List of Symbols}

\section{English Notation}

Bo Boiling number

Co Convection number

$\mathrm{Fr}_{\mathrm{le}} \quad$ Froude number

$\mathrm{Nu} \quad$ Nusselt number

$\operatorname{Pr} \quad$ Prandtl number

Re Reynolds number

$c_{\mathrm{p}} \quad$ Liquid specific heat, constant pressure $(\mathrm{J} / \mathrm{kg} \cdot \mathrm{K})$

$f \quad$ frequency of bubbles $(\mathrm{Hz})$

$h_{\text {fg }} \quad$ Latent heat $(\mathrm{J} / \mathrm{kg})$

$h \quad$ Heat transfer coefficient $\left(\mathrm{W} / \mathrm{m}^{2} \cdot \mathrm{K}\right)$

$k \quad$ Thermal conductivity $(\mathrm{W} / \mathrm{m} \cdot \mathrm{K})$

$m \quad$ Mass $(\mathrm{kg})$

$n_{\mathrm{a}} \quad$ Number of Active Nucleation Sites

$q " \quad$ Surface heat flux $\left(\mathrm{W} / \mathrm{m}^{2}\right)$

$t \quad$ Time (s)

$v \quad$ Velocity $(\mathrm{m} / \mathrm{s})$

$x \quad$ Void fraction or bubble position

$y \quad$ Distance from wall (m)

A Surface area $\left(\mathrm{m}^{2}\right)$

$D_{\mathrm{i}} \quad$ Tube inside diameter (m)

$G \quad$ Mass flow rate $\left(\mathrm{kg} / \mathrm{m}^{2}\right)$

$L \quad$ Tube length (m)

$N_{\mathrm{a}} \quad$ Active Nucleation Site Density $\left(1 / \mathrm{m}^{2}\right)$

$P \quad$ Pressure $(\mathrm{kPa})$

$Q \quad$ Energy (J)

$R \quad$ Bubble radius (m)

$T \quad$ Temperature (K)

$V \quad$ Bulk velocity $(\mathrm{m} / \mathrm{s})$

\section{Greek Symbols}

$\begin{array}{ll}\phi & \text { Surface contact angle }\left({ }^{\circ}\right) \\ \mu & \text { Dynamic viscosity }(\mathrm{Pa} \cdot \mathrm{s}) \\ v & \text { Kinematic viscosity }\left(\mathrm{m}^{2} \cdot \mathrm{s}\right)\end{array}$




$\begin{array}{ll}\rho & \text { Density }\left(\mathrm{kg} / \mathrm{m}^{3}\right) \\ \sigma & \text { Surface tension }(\mathrm{N} / \mathrm{m}) \\ \tau & \text { Shear stress }(\mathrm{Pa})\end{array}$

\section{Subscripts}

a

am

b

c

$\mathrm{cp}$

crit

d

ev

f,1

fc

fs

$\mathrm{g}$

$\mathrm{g}, \mathrm{V}$

i

in

1

nc

ni

out

qs

$\mathrm{r}$

$\mathrm{S}$

sat

sl

sp

sub

tc

$\mathrm{W}$

B

$\mathrm{S}$

\section{Superscripts}

Active nucleation site density

Added-mass force, or added mass (when using with $m$ )

Bubble

Cavity

Contact pressure force

Critical condition

Departure, or bubble diameter

Evaporation

Liquid

Forced convection

Free-stream acceleration force

Growth (when using with $t$ )

Vapor

Interaction

Inlet

Bubble lift-off

Natural convection

Non-interaction

Outlet

Quasi-steady drag

Radius

Sliding bubble

Saturated conditions

Shear lift force

Single phase heat transfer

Subcooled condition

Transient conduction

Wall/Fluid near the wall, or waiting time (when using with $t$ )

Bulk region, or buoyancy

Surface tension

\section{$+\quad$ Dimensionless equivalent of the physical property}




\section{Introduction}

In recent years, subcooled nucleate boiling (SNB) has attracted expanding research interest owing to the emergence of axial offset anomaly (AOA) or crud-induced power shift (CIPS) in many operating US PWRs, which is an unexpected deviation in the core axial power distribution from the predicted power curves. Research indicates that the formation of the crud, which directly leads to AOA phenomena, results from the presence of the subcooled nucleate boiling, and is especially related to bubble motion occurring in the core region. During the process of a bubble forming and growing on the clad surface, the bubble affects the flow field around it, forms a stagnant wake region, and results in accumulation of suspended particulates in the vicinity of its liquid-vapor interface. When the bubble leaves the heating surface, the attracted particulates remain on the surface. This is postulated eventually to result in the deposition of the suspended particulates, the precipitation of solutes and the formation of the crud, combined with complex chemical reactions.

For this reason, the nucleate boiling and the accompanying bubble motions have been extensively studied in the past. However, the basic theory of boiling remains largely unknown despite of the huge amount of work devoted to it. The main reason originates from the violence of the fluid motion that on the one hand conceals the mechanisms of bubble growth from detailed observation and on the other hand hugely complicates direct numerical simulations. Most still unanswered questions concern the close vicinity of the heating surface, down to the scale of bubbles growing at the surface of the heater especially during boiling at high heat fluxes common to industrial heat exchangers, e.g. fuel pins and steam generators in nuclear power plants.

The objective of the present investigation is to obtain a better understanding of subcooled nucleate flow boiling phenomena and the behavior of bubbles in the flow field from the dynamic point of view, and to provide better modeling on the heat transfer process from given heated surface information. The major question addressed in this project is how bubbles behave from a statistical point of view, and how motions of these groups of bubbles lead to critical heat flux. Analyses are performed on the dynamics of bubbles in the flow field, statistic interaction among groups of bubbles in clusters, and their effect on the surrounding flow field. Advanced visualization instruments are utilized for direct observation of the subcooled boiling process in the experiment apparatus, in order to assist the modeling approach. Data from simulant experiments are utilized to construct appropriate models. A model that consistently connects the macroscopic 
phenomena of boiling and the microscopic sub-processes of energy transport via the effects of the motion of bubbles is built to explain the mechanism of critical heat flux. 


\section{Project Accomplishments}

Introduced below, the third-year tasks for this grant emphasize on the modeling of bubble dynamics and bubble interactions, the formation of active bubble nucleation sites, and the bubble-induced convective heat transfer. The completed tasks are itemized and briefed below, followed by the details of the modeling approach and experimental verification. In the final section of the report, publications and references are given.

A statistical mechanistic model is built in this 3rd-year study that explains bubble interaction, bubble contribution to heat transfer, and critical heat flux due to limited bubble capacity. To verify the developed model, a spanning matrix of experiments with varying conditions including pressure, inlet sub-cooling, flow rate, and heat flux, has been undertaken on a smooth heating surface using the simulant fluid R-134a. Digital images of bubbles and flow field under the above conditions have been recorded and are under analysis. A maximum resolution of $3 \mu \mathrm{m} /$ pixel is achieved in observing and measuring bubble dimensions. The number of active bubble nucleation sites is measure for the aforementioned experimental conditions, to connect the macroscopic phenomena of boiling and the microscopic sub-processes of bubble-driven energy transport.

Completed phase 3 tasks are itemized below:

1) Developed a statistic mechanistic model that explains bubble motions and predicts bubble contributions to the subcooled nucleate boiling heat transfer;

2) Performed experimental verification of the model developed in 1) over a spanning matrix of experimental conditions that covers different pressure, temperature, and heat flux conditions;

3) Repeated experiments in 2) to measure the active bubble nucleation site densities and study the effect of the experimental conditions;

4) Compared model prediction with the existing data in literature of different working fluids and confirmed its extended application.

Phase 3 deliverable will include:

1) Development of the stochastic bubble interaction model;

2) Development of the model that predicts the flow boiling heat transfer based on the stochastic bubble interaction modeled in 1);

3) Experimental data that verifies the model developed in 1) and 2), i.e, the comparison between the model prediction and the experimental data;

4) Improved boiling model with incorporation of non-zero flow field; 


\section{Model Development}

A model is developed to predict the overall wall heat flux from given wall superheat, i.e., to predict the boiling curve, from single phase forced convection region up to critical heat flux (CHF). In this mechanism-based prediction, each and every component of the wall heat flux is identified and then computed independently. To achieve this goal, the boiling process is decomposed into several sub-processes and described with appropriate sub-models, correspondingly.

Key assumptions and results of the model development are introduced in this report. For details of the model developing process please refer to [1].

\subsection{Bubble Interaction (Coalescence) Probability}

\subsubsection{Basic Assumptions}

When there is more than one bubble staying on the heated surface in boiling, during bubble growth and bubble movement one may interact (coalesce) with another on the heating surface if they are sufficiently close. In this study of developing the stochastic bubble interaction probability, an assumption of coalesce-lift-off is made for modeling bubble interaction probabilities, in which the newly formed bubble directly leaves the heated surface and enters the bulk region. It is experimentally observed to be the preferred case when two bubbles interact.

Additional assumptions are required to compose a statistical model to explain bubble interaction quantitatively. First, the active nucleation sites are assumed to have a uniform distribution on the whole heated surface, which is approximately true when the heat flux is sufficiently high so that the number of the active sites is large $\left(\sim 10^{7-8} / \mathrm{m}^{2}\right)$. Second, bubbles originating from any single nucleation site are assumed to be generated at a constant frequency $f_{\mathrm{b}}$, which can be calculated from the bubble departure and lift-off model by Thorncroft et al. [2]. Third, the condition for two-bubble interaction is defined to be two perfectly spherical bubbles being intersecting with each other in 3-D space.

\subsubsection{Probabilities of Two-Bubble Interaction}

Shown in Fig. 1, each bubble starting from its generation is assumed to stay on its bubble site for $t_{\mathrm{d}}$, and then slide along the heating surface with a certain sliding velocity from $t_{\mathrm{d}}$ to $t_{1}$, which can be calculated from the derivation of $x(t)$. The bubble leaves the heated surface at $t_{1}$. 


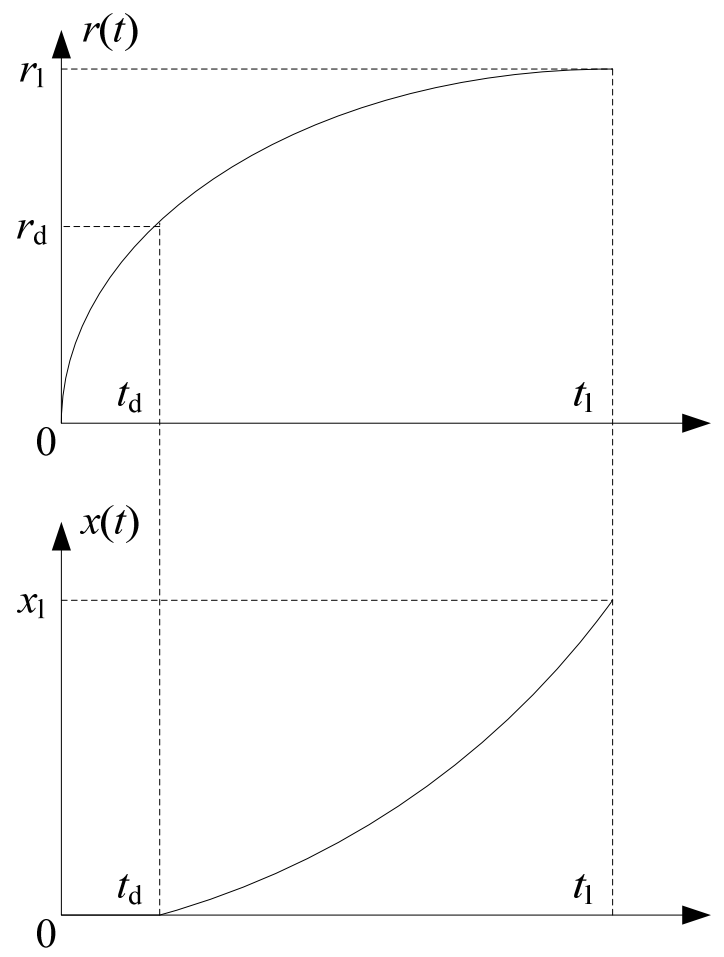

Fig. 1. Simplified Bubble Growth and Bubble Sliding Curves

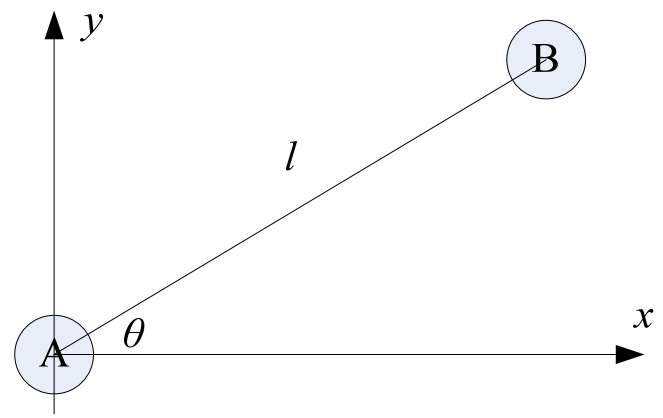

Fig. 2. Bubble Relative Position

Consider the 3-D distance between the bubbles in Fig. 2, for a bubble A generated at $t=0, \vec{u}=0$, and a bubble $\mathrm{B}$ generated at $t=\tau, \vec{v}=\hat{x} \cdot l \cos \theta+\hat{y} \cdot l \sin \theta$, the condition of A interacting with B at time $t$ for $t>0$ is,

$|\vec{v}(t)-\vec{u}(t)| \leq r(t)+r(t-\tau)$, for $t-t_{1} \leq \tau \leq t$

Rearrange to obtain

$l_{1} \leq l \leq l_{2}$

in which

$l_{1,2}=\cos \theta[x(t)-x(t-\tau)] \mp \sqrt{4 r(t) r(t-\tau)-\sin ^{2} \theta[x(t)-x(t-\tau)]^{2}}$

By assuming that $\mathrm{B}$ is generated within the range of $\left[0, x_{1}\right], l$ is a random variable evenly distributed within $\left[0, x_{1}\right]$. Therefore, the probability of A interacting with $\mathrm{B}$ during its life span is 


$$
P_{\mathrm{i} ; \mathrm{B}}=\frac{\int_{0}^{t_{1}} d t \int_{t-t_{1}}^{t} d \tau \int_{0}^{2 \pi} d \theta 2 \sqrt{4 r(t) r(t-\tau)-\sin ^{2} \theta[x(t)-x(t-\tau)]^{2}}}{\int_{0}^{t_{1}} d t \int_{t-t_{1}}^{t} d \tau \int_{0}^{2 \pi} d \theta x_{1}}
$$

Rearrange to obtain

$$
P_{\mathrm{i} ; \mathrm{B}}=\int_{0}^{t_{1}} d t \int_{t-t_{1}}^{t} d \tau \int_{0}^{2 \pi} d \theta\left\{\frac{1}{\pi t_{1}^{2} x_{1}} \sqrt{4 r(t) r(t-\tau)-\sin ^{2} \theta[x(t)-x(t-\tau)]^{2}}\right\}
$$

If it is assumed that $\mathrm{B}$ is generated within the range of $[0, L]$, where $L$ is the average distance between two adjacent nucleation site, the probability of A interacting with $\mathrm{B}$ during its life span is given as

$$
P_{\mathrm{i}}=\int_{0}^{t_{1}} d t \int_{t-t_{1}}^{t} d \tau \int_{0}^{2 \pi} d \theta\left\{\frac{1}{\pi t_{1}^{2} L} \sqrt{4 r(t) r(t-\tau)-\sin ^{2} \theta[x(t)-x(t-\tau)]^{2}}\right\}
$$

the probability of A not interacting with B during its life span is given as

$$
\begin{aligned}
P_{\mathrm{ni}} & =1-\int_{0}^{t_{1}} d t \int_{t-t_{1}}^{t} d \tau \int_{0}^{2 \pi} d \theta\left\{\frac{1}{\pi t_{1}^{2} L} \sqrt{4 r(t) r(t-\tau)-\sin ^{2} \theta[x(t)-x(t-\tau)]^{2}}\right\} \\
& =\int_{0}^{t_{1}} d t \int_{t-t_{1}}^{t} d \tau \int_{0}^{2 \pi} d \theta\left\{\frac{0.5 L-\sqrt{4 r(t) r(t-\tau)-\sin ^{2} \theta[x(t)-x(t-\tau)]^{2}}}{\pi t_{1}^{2} L}\right\}
\end{aligned}
$$

The probability density function $(p d f)$ of A interacting with B by definition is

$p_{\mathrm{i}}(t, \theta, \tau)=\frac{1}{\pi t_{1}^{2} L} \sqrt{4 r(t) r(t-\tau)-\sin ^{2} \theta[x(t)-x(t-\tau)]^{2}}$

By integrating over $\theta$ and $\tau$, the $p d f$ of A interacting with any single bubble is given as

$$
p_{\mathrm{i}}(t)=\int_{t-t_{1}}^{t} d \tau \int_{-\pi}^{\pi} d \theta \cdot p_{\mathrm{i}}(t, \theta, \tau)
$$

Correspondingly, the cumulative distribution function is

$$
P_{\mathrm{i}}(t)=\int_{0}^{t} d t \cdot p_{\mathrm{i}}(t)
$$

The probability density function $(p d f)$ of A not interacting with B by definition is

$$
p_{\mathrm{ni}}(t, \theta, \tau)=\frac{1}{\pi t_{1}^{2} L}\left(\frac{L}{2}-\sqrt{4 r(t) r(t-\tau)-\sin ^{2} \theta[x(t)-x(t-\tau)]^{2}}\right)
$$

By integrating over $\theta$ and $\tau$, the unconditional $p d f$ of A interacting with any single bubble 
is given as

$$
\begin{aligned}
p_{\mathrm{ni}}(t) & =\int_{t-t_{1}}^{t} d \tau \int_{-\pi}^{\pi} d \theta \cdot p_{\mathrm{ni}}(t, \theta, \tau) \\
& =\frac{1}{t_{1}}-p_{\mathrm{i}}(t)
\end{aligned}
$$

The corresponding cumulative distribution function is

$$
P_{\mathrm{ni}}(t)=\int_{0}^{t} d t \cdot p_{\mathrm{ni}}(t)
$$

\subsubsection{Probabilities of Multiple Interactions During Bubble Life Span}

The number of bubbles that potentially can interact with bubble A along the path swept by A can be calculated by

$$
N_{\mathrm{b}} \approx \frac{t_{1}}{t_{\mathrm{d}}+t_{\mathrm{w}}} \cdot \frac{\left(t_{1}-t_{\mathrm{d}}\right) V_{\mathrm{s}}+r_{1}+\bar{r}_{1}}{L} \approx \frac{t_{1}}{t_{\mathrm{d}}+t_{\mathrm{w}}} \cdot \frac{\left(t_{1}-t_{\mathrm{d}}\right) V_{\mathrm{s}}+\frac{5}{3} r_{1}}{L}
$$

The first term is the average number of bubbles that can be generated from a nucleation site during the bubble life span, while the second term is the average number of nucleation sites that the trajectory of a sliding bubble can cover.

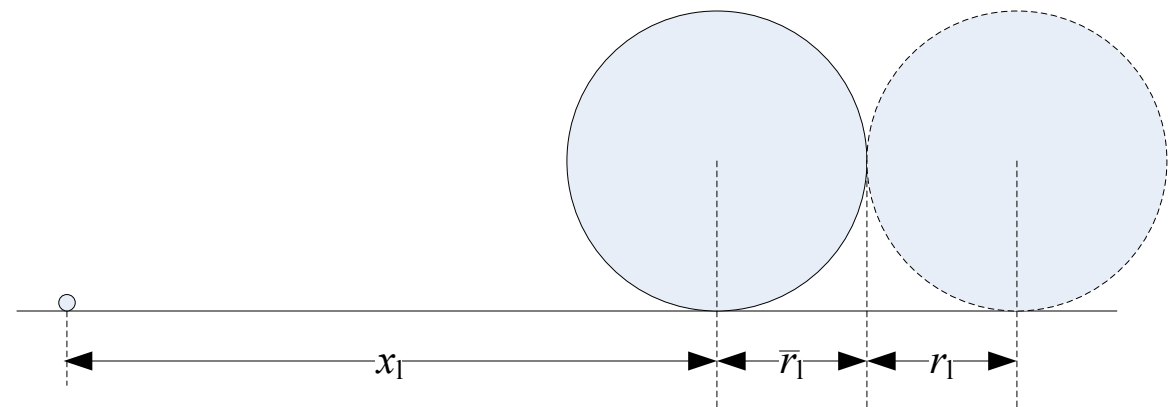

Fig. 3. Influence of Bubble during its Sliding

Therefore, the cumulative distribution function of a bubble not interacting with any one of these $N_{\mathrm{b}}$ bubbles during its sliding is

$$
P_{\mathrm{ni}, N_{\mathrm{b}}}(t)=P_{\mathrm{ni}}^{N_{\mathrm{b}}}(t)
$$

The $p d f$ of a bubble not interacting with any one of these $N_{\mathrm{b}}$ bubbles during its sliding is $p_{\mathrm{ni}, N_{\mathrm{b}}}(t)=\frac{d}{d t} P_{\mathrm{ni}, N_{\mathrm{b}}}(t)=N_{\mathrm{b}} P_{\mathrm{ni}}^{N_{\mathrm{b}}-1}(t) p_{\mathrm{ni}}(t)$

Similarly, the cumulative distribution function of a bubble interacting with any of these $N_{\mathrm{b}}$ bubbles during its sliding is 
$P_{\mathrm{i}, N_{\mathrm{b}}}(t)=\left(\frac{t}{t_{1}}\right)^{N_{\mathrm{b}}}-P_{\mathrm{ni}, N_{\mathrm{b}}}(t)$

The $p d f$ of a bubble interacting with any of these $N_{\mathrm{b}}$ bubbles during its sliding is:

$$
p_{\mathrm{i}, N_{\mathrm{b}}}(t)=\frac{d}{d t} P_{\mathrm{i}, N_{\mathrm{b}}}(t)=\frac{N_{\mathrm{b}} t^{N_{\mathrm{b}}-1}}{t_{1}^{N_{\mathrm{b}}}}-\frac{d}{d t} P_{\mathrm{ni}, N_{\mathrm{b}}}(t)=\frac{N_{\mathrm{b}} t^{N_{\mathrm{b}}-1}}{t_{1}^{N_{\mathrm{b}}}}-N_{\mathrm{b}} P_{\mathrm{ni}}^{N_{\mathrm{b}}-1}(t) p_{\mathrm{ni}}(t)
$$

\subsubsection{Conditional Bubble Interaction Probability and Ergodic Principle}

Based on the coalesce-lift-off assumption, for a bubble that actually interacts with another bubble at time $t$, it it should not interact with any bubbles during time interval [0, $t$ ). Therefore, the conditional $p d f$ of a bubble interacting with other bubbles is the unconditional $p d f$ divided by the probability that it didn't interact with any of these bubbles during $[0, t)$, which is given by

$$
p_{\mathrm{i}, \mathrm{c}}(t)=\frac{p_{\mathrm{i}, N_{\mathrm{b}}}(t)}{P_{\mathrm{ni}, N_{\mathrm{b}}}(t)}=\frac{N_{\mathrm{b}}}{t_{1}^{N_{\mathrm{b}}}} \frac{t^{N_{\mathrm{b}}-1}-t_{1}^{N_{\mathrm{b}}} P_{\mathrm{ni}}^{N_{\mathrm{b}}-1}(t) p_{\mathrm{ni}}(t)}{P_{\mathrm{ni}}^{N_{\mathrm{b}}}(t)}
$$

If we discretize $t$ into $N_{\mathrm{g}} \Delta t$ intervals, then

$$
p_{\mathrm{i}, \mathrm{c}} \doteq p_{\mathrm{i}, \mathrm{c}}\left(t_{i}\right) \Delta t
$$

is the probability of a bubble leaving the heated surface during the $\left[t_{\mathrm{i}}, t_{\mathrm{i}}+\Delta t\right)$ interval.

From the ergodic principle, if a total of $N_{\mathrm{b}}$ bubbles are observed simultaneously, $p_{\mathrm{i}, \mathrm{c}}$ can be interpreted as the portion of $N_{\mathrm{b}}$ bubbles in the $\mathrm{i}^{\text {th }}$ group that leave the heated surface at $t_{\mathrm{i}}$ as the result of bubble interaction. From this interpretation, bubbles on the heated surface can be treated as if there are simply $N_{\mathrm{g}}$ groups of bubbles, with each group containing a certain portion $\left(p_{\mathrm{i}, \mathrm{c}}\right)$ of the whole number. In each group, bubbles behave the same by staying on the heated surface for $t_{\mathrm{i}}$ and then lift off.

\subsection{Mechanisms of Flow Boiling Heat Transfer}

The heat transfer mechanisms accompanying with the bubble motion described in Section 3.1 can be identified as the force convection, the transient conduction, and the micro-layer evaporation, which are computed independently. The fundamental principle lies in that energy from the wall is first transferred to the liquid layer adjacent to the heated wall and thereafter from this superheated liquid layer, energy is transferred to the vapor bubble by evaporation while the remainder goes to the bulk liquid.

\subsubsection{Forced Convection}

Forced convection heat flux are computed from the widely accepted formula,

$q_{\mathrm{fc}}=h_{\mathrm{fc}}\left(T_{\mathrm{w}}-T_{\mathrm{B}}\right)$ 
The Dittus-Boelter equation [3] given by

$\mathrm{Nu}=0.023 \mathrm{Re}^{0.8} \operatorname{Pr}^{0.4}$

is first used to calculate $\mathrm{Nu}$ and then from the definition of $\mathrm{Nu}, h_{\mathrm{fc}}$ is calculated from

$h_{\mathrm{fc}}=\frac{\mathrm{Nu} \cdot k_{1}}{D_{\mathrm{h}}}$

\subsubsection{Transient Conduction}

Both bubble lift-off and bubble sliding are associated with transient conduction.

This is due to the disrupted boundary layer and because colder liquid comes from the surrounding region to fill in the region occupied by the moving (including sliding and lift-off) bubble. The transient conduction process is modeled as one-dimensional transient heat conduction into a semi-infinite medium, with the bulk liquid at temperature $T_{\text {sat }}$ and heater surface at temperature $T_{\mathrm{w}}$. Based on the error function solution of the transient temperature profile, the transient conduction heat flux at the wall can be expressed as

$q_{\mathrm{tc}}=\frac{k_{1}\left(T_{\mathrm{w}}-T_{\mathrm{sat}}\right)}{\sqrt{\pi \alpha_{1} t}}$

When a vapor bubble accelerates during its sliding and lift-off, acceleration is also imposed on its surrounding fluid flow due to the inertial effect of the fluid. Equivalently, the bubble behaves as if it carries a certain amount of surrounding liquid on its interface with its motion. A concept of "added mass" was proposed to account for this effect and to evaluate the necessary work done to change the kinetic energy associated with the fluid motion [4]. For a purely spherical bubble, the added mass is

$m_{\mathrm{am}}=\frac{2 \pi}{3} r_{1}^{3} \rho_{1}$

which is one-half of the displaced mass of the fluid.

By assuming that the added liquid mass is uniformly attached to the vapor-liquid interface as an approximation, a virtual bubble radius of $1.5^{1 / 3} r_{1}$ is used to replace $r_{1}$ in calculating the surface area on which transient conduction occurs, in order to incorporate the added mass effect. Judd and Huang [5] suggested a value of $1.8^{1 / 2}$ to match their experimental data, which was adopted by Sateesh et al. [6]. In Basu et al.'s model [7], however, this effect was completely neglected.

\subsubsection{Microlayer Evaporation}

Bubbles gain vapor from evaporation of both the microlayer and superheated thermal boundary layer during their growth. The contribution from microlayer evaporation $\left(q_{\mathrm{me}}\right)$ upon lift-off of a vapor bubble is the amount of latent heat required for 
generation of the vapor bubble of its size $r_{1}$ which can be expressed as

$q_{\mathrm{me}}=\frac{4 \pi}{3} r_{1}^{3} \cdot \rho_{\mathrm{v}} h_{\mathrm{fg}}$

\subsection{Energy Conservation Revisit}

From Section 3.1.4, considering the effect of bubble interaction is equivalent to considering $N_{\mathrm{g}}$ groups of bubbles, with each group containing $N p_{\mathrm{i}, \mathrm{c}}$ identical bubbles behaving as if there is no interaction at all. Based on the $N_{\mathrm{g}}$ groups of identical bubbles, different components of the heat flux can be calculated. The expressions for each of them are summarized in Table 1 below.

Table 1. Expressions for Different Heat Flux Components

\begin{tabular}{|l|l|}
\hline$q_{\mathrm{me}}$ & $\frac{4}{3} \pi \mathrm{r}_{\mathrm{i}}^{3} \rho_{\mathrm{v}} h_{\mathrm{fg}} N_{\mathrm{a}} f_{\mathrm{i}} p_{\mathrm{i}, \mathrm{c}}$ for each group \\
\hline$q_{\mathrm{tc}}$ & $\frac{2 k_{1}}{\sqrt{\pi \alpha_{1}}} \Delta T_{\mathrm{sat}} N_{\mathrm{a}} f_{\mathrm{i}} p_{\mathrm{i}, \mathrm{c}} \pi\left(C_{\mathrm{r}} r_{\mathrm{i}}\right)^{2} \sqrt{\min \left(t_{\mathrm{i}, \mathrm{w}}, t^{+}\right)}$for each non-sliding group \\
\hline$q_{\mathrm{tcs}}$ & $\frac{2 k_{1}}{\sqrt{\pi \alpha_{1}}} \Delta T_{\mathrm{sat}} N_{\mathrm{a}} f_{\mathrm{i}} \sqrt{\min \left(t_{\mathrm{g}}+t_{\mathrm{i}, \mathrm{w}}, t^{+}\right)}\left\{p_{\mathrm{i}, \mathrm{c}} \pi\left(C_{\mathrm{r}} r_{\mathrm{i}}\right)^{2}+\sum_{\mathrm{j}=\mathrm{i}}^{N_{\mathrm{g}}} p_{\mathrm{j}, \mathrm{c}} 2\left(C_{\mathrm{r}} r_{\mathrm{i}}\right) V_{\mathrm{s}} \Delta t\right\} \quad$ for \\
& each sliding group \\
\hline$q_{\mathrm{fc}}$ & $\begin{array}{l}h_{\mathrm{fc}}\left(T_{\mathrm{w}}-T_{1}\right) N_{\mathrm{a}} p_{\mathrm{i}, \mathrm{c}} \pi\left(C_{\mathrm{r}} r_{\mathrm{i}}\right)^{2} \max \left(0,1-\frac{t^{+}}{t_{\mathrm{i}, \mathrm{w}}}\right) \text { for each non-sliding group } \\
h_{\mathrm{fc}}\left(T_{\mathrm{w}}-T_{1}\right) N_{\mathrm{a}} p_{\mathrm{i}, \mathrm{c}} 2\left(C_{\mathrm{r}} r_{\mathrm{i}}\right) V_{s} \Delta t \max \left(0,1-\frac{t^{+}}{t_{\mathrm{g}}+t_{\mathrm{i}, \mathrm{w}}}\right) \text { for each sliding group }\end{array}$ \\
& $h_{\mathrm{fc}} A_{\mathrm{r}}\left(T_{\mathrm{w}}-T_{1}\right)$ on the remained heated surface not covered by bubbles \\
\hline
\end{tabular}

\subsection{Critical Heat Flux}

Prediction of Critical Heat Flux (CHF) is a natural extension of the prediction of heat fluxes as $T_{\mathrm{w}}$ continues to increase. As $T_{\mathrm{w}}$ increases, $N_{\mathrm{a}}, r_{\mathrm{d}}$, and $r_{1}$ are all predicted to increase, resulting in an increasingly populated heated surface. Bubbles are inclined to interact with others during the early stage of their life span. Eventually, bubbles are arranged on the heated surface at the most compact pattern with very little sliding being allowed. Their average size is confined by the average separation distance of the nucleation sites. In this extreme case, this model predicts the maximum heat flux at which the heated surface reaches its maximum heat transfer capacity. 


\subsection{Improved Heat Transfer Model Based on Bubble Motions}

This improved heat transfer predictive model is a composite of several sub-models with each of them addressing one sub-process. As is shown in Fig. 4, a top-down decomposition of this model explains the function of each sub-model and their dependencies. The core component of this model, the calculation of the bubble interaction probability, has been introduced in Section 3.1.

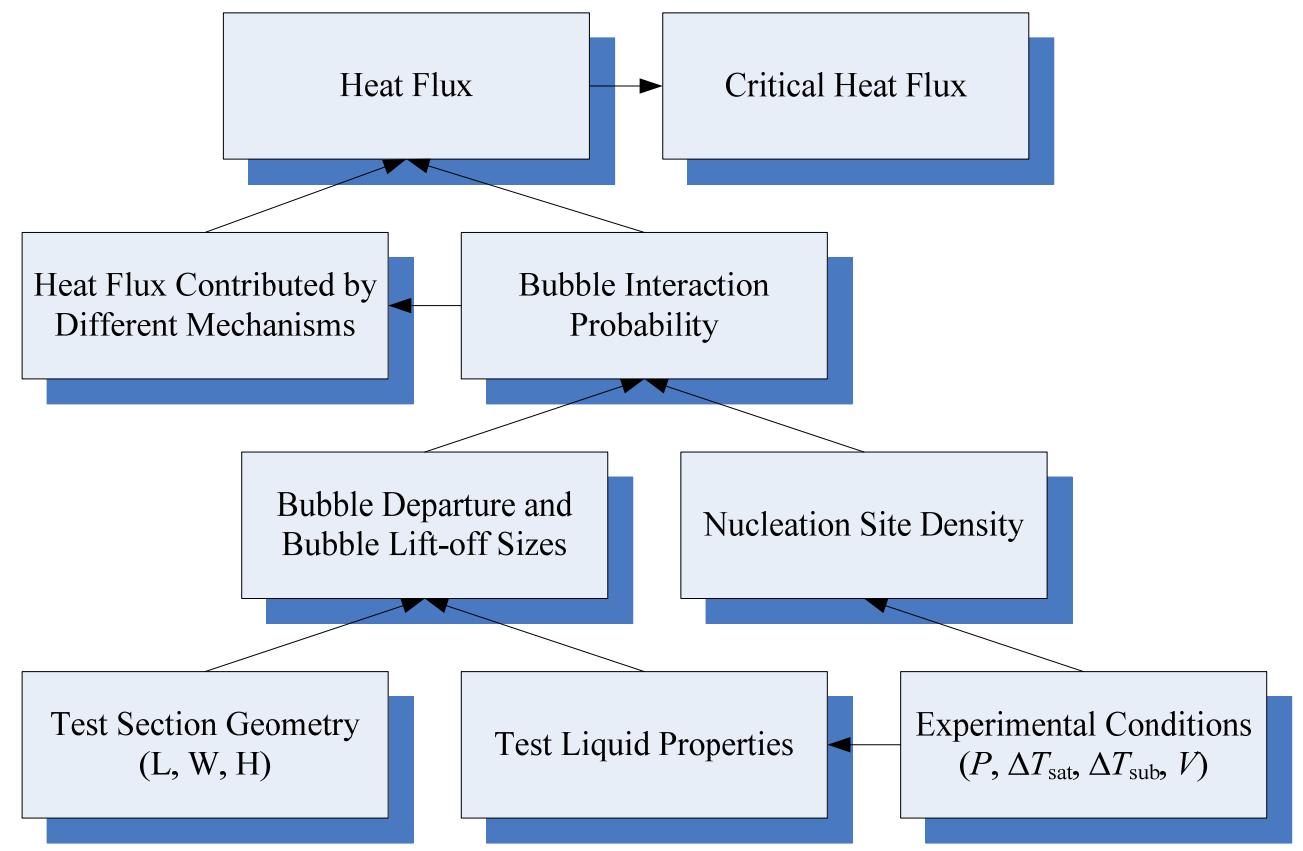

Fig. 4. Data Dependency of the Model

A computer code written in MATLAB is used to implement this model and to perform predictions based on given experimental conditions. In the first portion of this code, required parameters, e.g. test liquid properties, are prepared from given experimental conditions. Then, combining with the test section geometry, critical bubble sizes, e.g. bubble departure and lift-off diameters, and the nucleation site density are predicted, which are in turn fed into next portion of the code to compute the conditional bubble interaction probability, which gives the information for each group of the bubbles. Based on this information, heat flux components contributed to by different mechanisms are calculated subsequently to obtain the total heat flux. At sufficiently high wall superheat, the predicted result of the heat flux, which is observed to remain nearly unchanged, gives the prediction of CHF. 


\section{Model Validation}

Verification of the model proposed in Chapter 3 is given in this chapter. Results are shown for the measurement of nucleation site density on the heated surface, followed by bubble growth, critical bubble sizes, and their distributions. In the last section of this chapter, theoretical prediction of the boiling curve is compared with the experimental results.

\subsection{Active Nucleation Site Density}

Digital images are taken by a Canon 20D digital camera and processed automatically by computer to obtain the active nucleation site density. Fig. 5 shows a typical image before and after processing for the measurement of the nucleation site density.
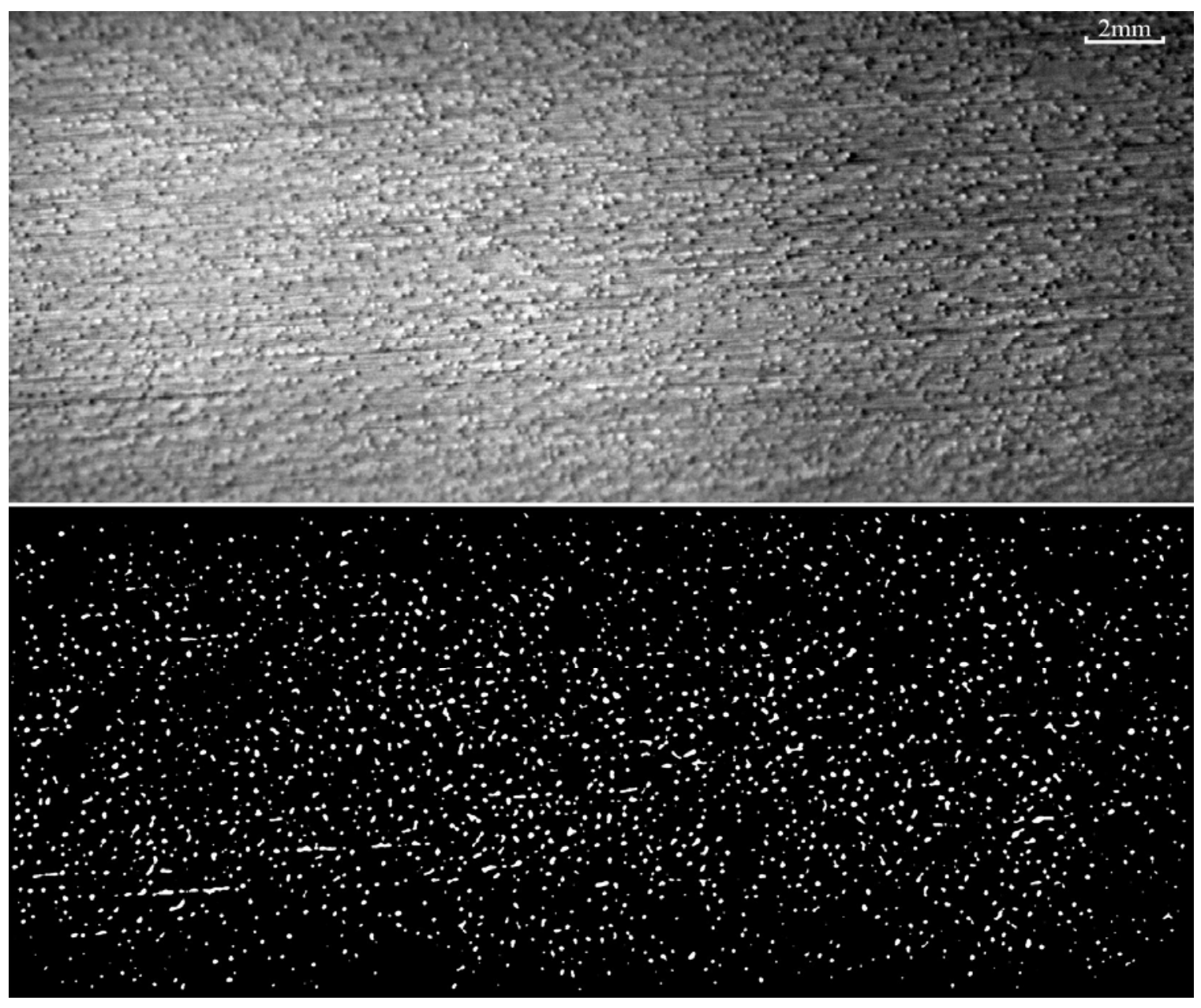

Fig. 5. Typical Results on Nucleation Site Density

Data is measured at P: $300 \mathrm{Kpa}, \Delta T_{\text {sub }}: 15.12^{\circ} \mathrm{C}, v: 0.205 \mathrm{~m} / \mathrm{s} ; \Delta T_{\mathrm{w}}: 9.57^{\circ} \mathrm{C}$. Measured Nucleation Site Density: 6.97 sites $/ \mathrm{mm}^{2}$, average error: $\pm 7.0 \%$. 
Fig. 6 shows a comparison of the $N_{\mathrm{a}}$ values measured under different pressures with varying heated surface temperature for static contact angle $\theta=40^{\circ}$ (typical value of the static contact angle for the combination of R134a and copper). At high wall superheats, it is typically difficult to measure the exact number of nucleation sites due to bubble motion and bubble coalescence on the heated surface and in the bulk region. Higher vapor quality also leads to changes of the liquid refraction index and change of equivalent object distance and results in out-of-focus images. Most of the experiments were conducted in the range $3^{\circ} \mathrm{C} \leq \Delta T_{\text {sat }} \leq 13^{\circ} \mathrm{C}$ (corresponding to $1 \mu \mathrm{m} \geq D_{\mathrm{c}} \geq 0.2 \mu \mathrm{m}$ ).

Based on the present data, a correlation is developed for $N_{\mathrm{a}}$ as a function of both critical diameter $D_{\mathrm{c}}$ and static contact angle $\theta$ by borrowing the form of the formula proposed by Basu, et al. [8]. It is given as:

$$
N_{\mathrm{nc}}=4.114 \times 10^{-6}(1-\cos \theta) D_{\mathrm{c}}^{-2.0}
$$

which is very similar to their proposed formula for low wall superheat range but with a different constant due to the usage of different test liquids.

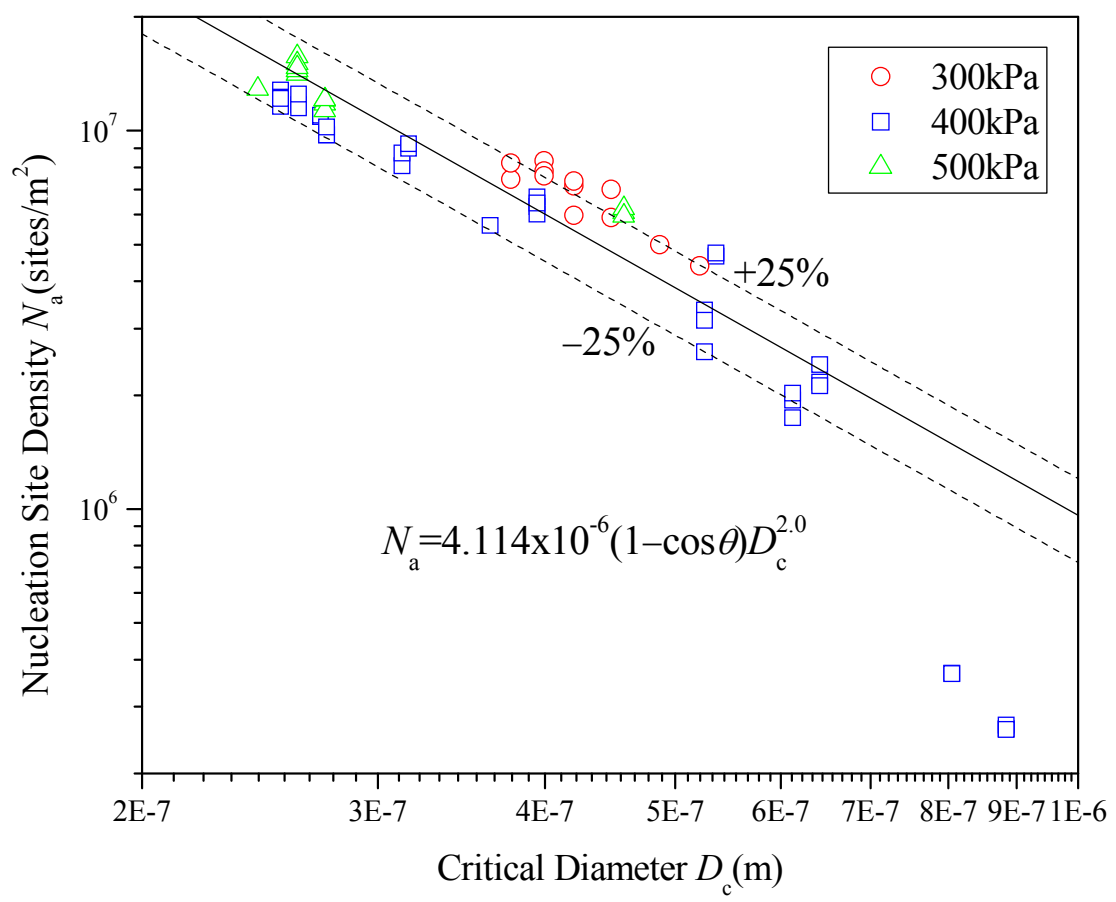

Fig. 6. Measured Nucleation Site Density 


\subsection{Bubble Growth}

\subsubsection{Measured Bubble Growth Rate}

Typical sets of experimentally measured growth curves at $400 \mathrm{kPa}$ are depicted in Fig. 7. The growth curve is obtained by measuring the size of an individual bubble from incipience through sliding. The relative error of the bubble-related measurement is represented by the size of the symbols, which is estimated to be strictly less than $3.9 \%$ for a typical bubble radius of $50 \mu \mathrm{m}$, by assuming a constant error of 0.5 pixels $(=1.95 \mu \mathrm{m})$ during discretization in the imaging process. Prediction from Mikic's model is also shown for comparison.

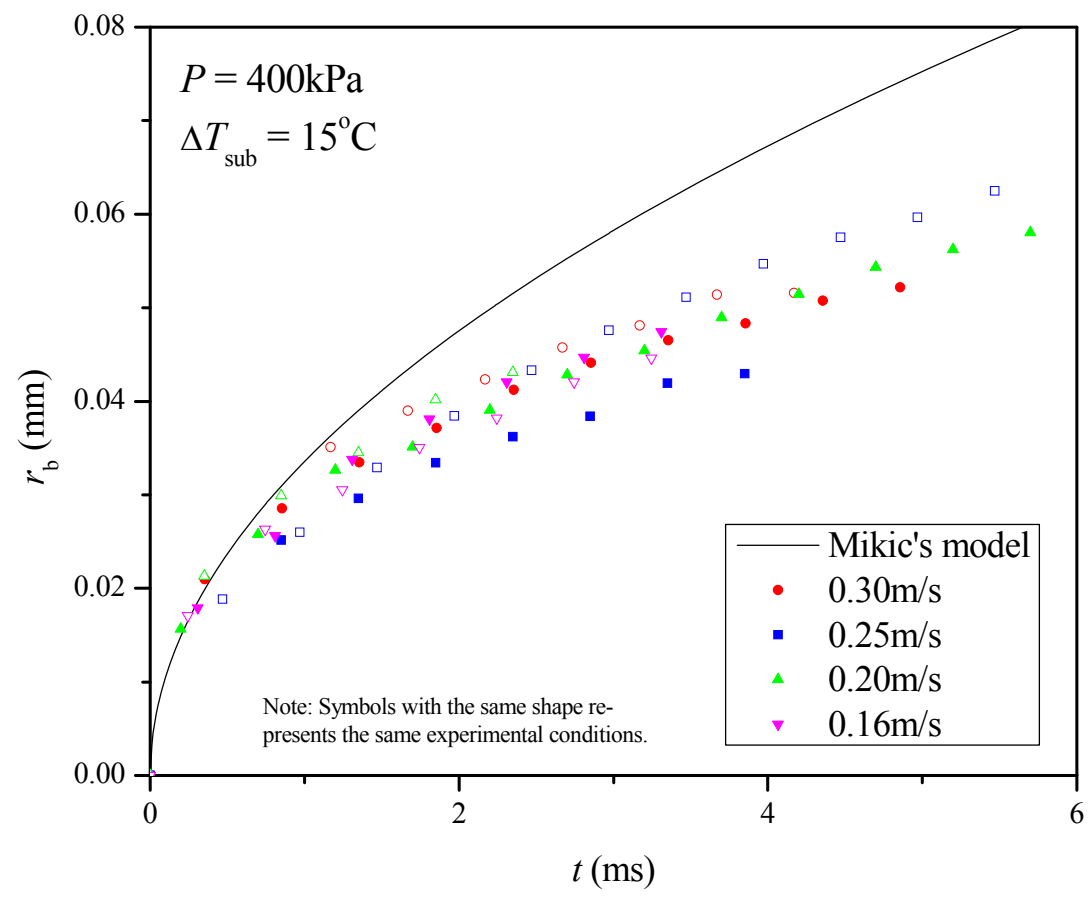

Fig. 7. Measured Bubble Growth at $400 \mathrm{kPa}$

\subsection{Results on Bubble Departure and Bubble Lift-off}

\subsubsection{Bubble Departure Radius}

The vapor bubble radius upon departure can be computed from given experimental conditions by the model proposed by Thorncroft et al. [2]. When the wall superheat $\Delta T_{\mathrm{w}}$ is fixed, the departure radius is a function of only the mean flow velocity. Fig. 8 shows the measurement of bubble departure radius as a function of mean flow velocity with the wall superheat maintained in a range of $4.63-5.89^{\circ} \mathrm{C}$. Measurements were made at $400 \mathrm{kPa}$, $10^{\circ} \mathrm{C}$ inlet sub-cooling. For comparison, the model predicted departure radii are also 
displayed. Good agreement is achieved between the model prediction and the experimental results.

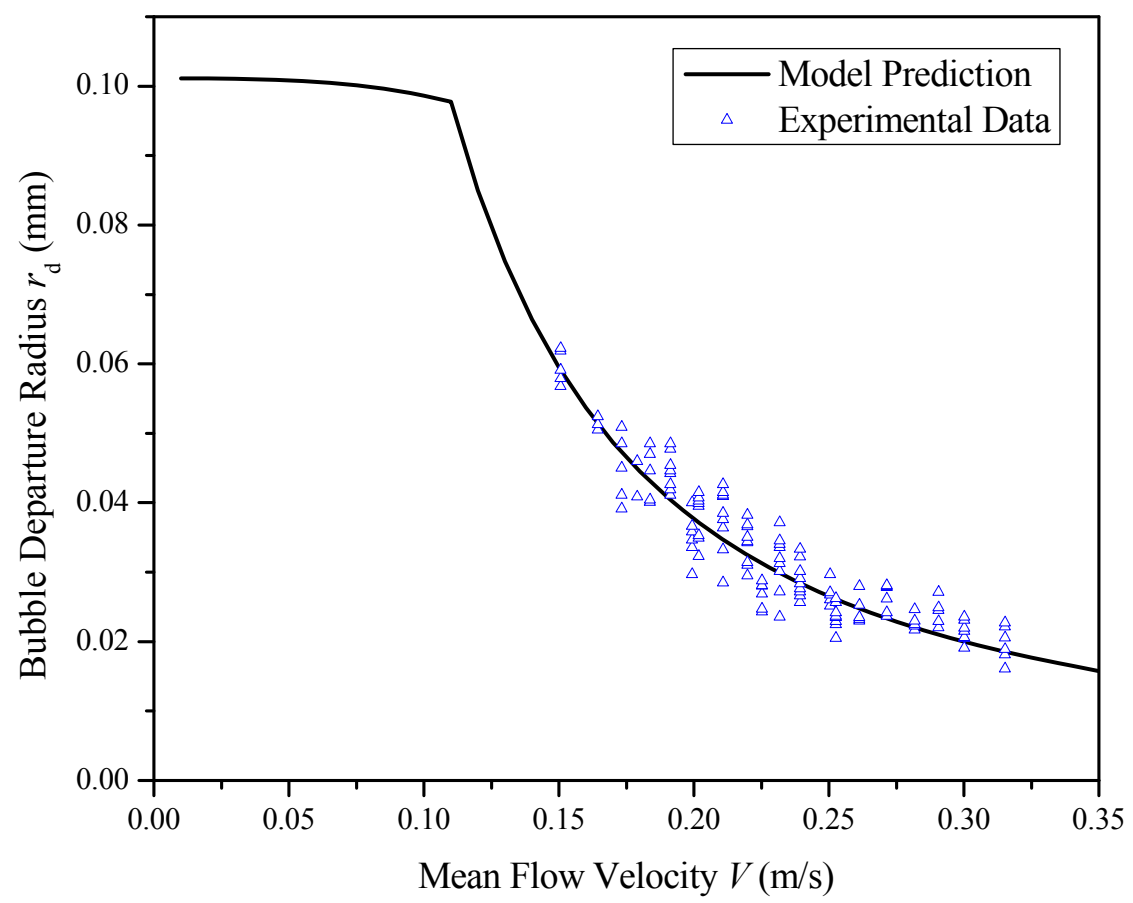

Fig. 8. Bubble Departure Radius with Varying Liquid Velocity at Fixed $\Delta T_{\text {sat }}$

\subsubsection{Bubble Lift-Off Radius}

Fig. 9 gives the distribution of the normalized sliding velocity for all measured lift-off bubbles. It is observed that its distribution generally obeys a Gaussian distribution centered at $r=0.512$ with most data spread over the range of [0.35, 0.65]. Fig. 10 shows the bubble lift-off radius with varying mean flow velocities for the $\Delta T_{\mathrm{w}}$ range of $4.63-5.89^{\circ} \mathrm{C}$, the same as in bubble departure radius measurement. Prediction is given to a normalized sliding velocity being 0.50 . The other two curves, calculated for $r$ being 0.35 and 0.65 , are also displayed for reference. 


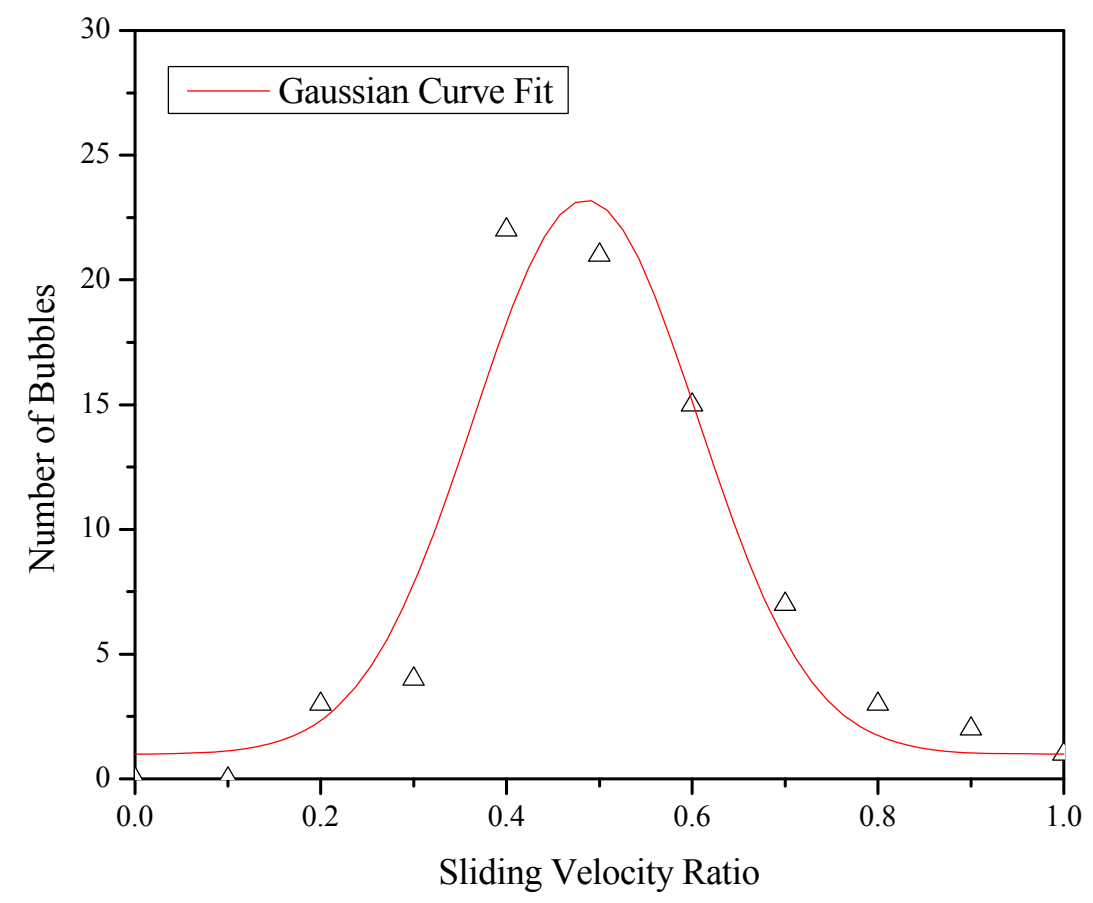

Fig. 9. Bubble Sliding Velocity Distribution

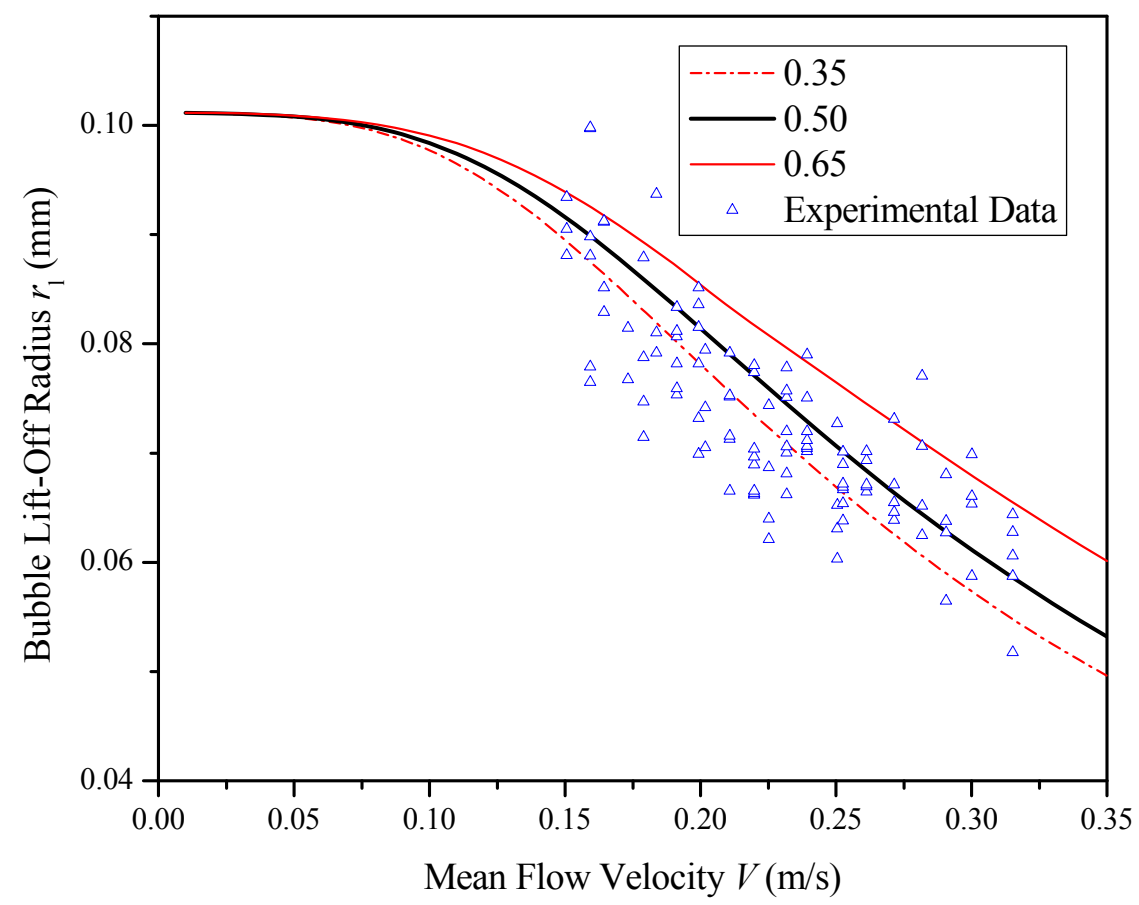

Fig. 10. Bubble Lift-Off Radius with Varying Liquid Velocity at Fixed $\Delta T_{\text {sat }}$ 


\subsection{Model Prediction on Boiling Curves}

\subsubsection{Experimental Data Overview}

Experimental observations of bubble movement and wall heat transfer are made for a range of pressures, inlet subcoolings, and velocities. A total of twenty-nine sets of data are measured under these conditions, as is shown in Table 2.

Table 2. Test Numbers and Their Corresponding Conditions

\begin{tabular}{|c|c|c|c|c|c|c|c|c|c|c|}
\hline$T_{\mathrm{w}}-T_{\text {in }}\left({ }^{\circ} \mathrm{C}\right)$ & \multicolumn{3}{|c|}{10} & \multicolumn{4}{|c|}{23} & \multicolumn{3}{|c|}{33} \\
\hline$V(\mathrm{~m} / \mathrm{s})$ & 0.4 & 0.6 & 0.8 & 0.4 & 0.6 & 0.8 & 1.0 & 0.6 & 0.8 & 1.0 \\
\hline 0.09 & EX7 & EX16 & EX27 & EX10 & EX8 & EX22 & - & EX15 & EX9 & EX21 \\
\hline 0.16 & EX1 & EX17 & EX26 & EX11 & EX2 & EX23 & EX29 & EX14 & EX3 & EX20 \\
\hline 0.25 & EX6 & EX18 & EX25 & EX12 & EX5 & EX24 & EX28 & EX13 & EX4 & EX19 \\
\hline
\end{tabular}

Fig. 11 shows the twenty-nine boiling curves corresponding to the above test conditions. Typical error is estimated to be $\pm 0.2^{\circ} \mathrm{C}$ for $T_{\mathrm{w}}-T_{\text {sat }}$ and $\pm 2.86 \%$ for $q$ ", which is represented by the data symbol size. 


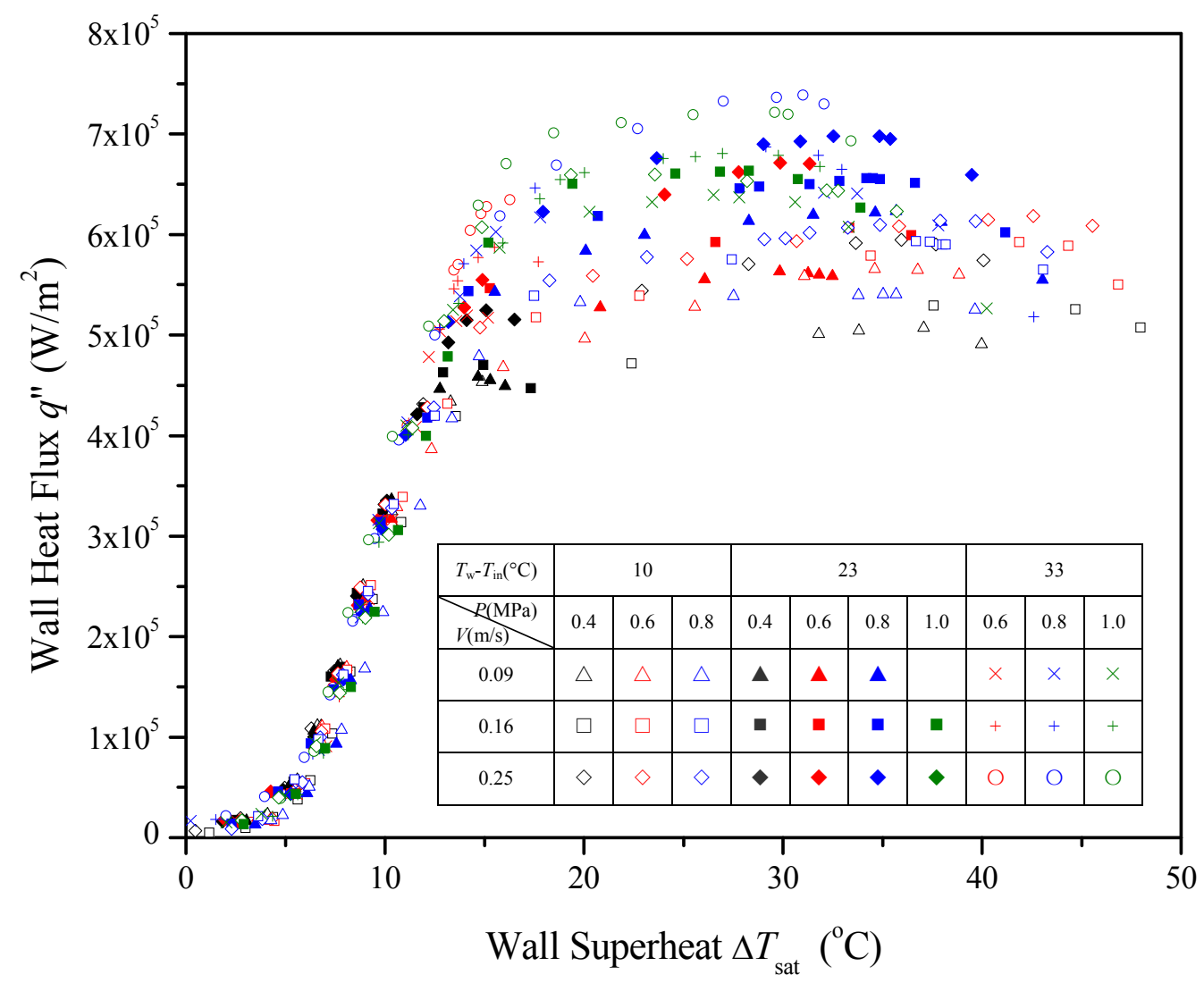

Fig. 11. Measured Boiling Curves under Different Experimental Conditions

\subsubsection{Comparison for R134a Data with Model Predictions at 400kPa}

The model is compared against the collected experimental heat flux data. Fig. 12 shows the model prediction of boiling curves at $400 \mathrm{kPa}$, with varying mean flow velocities and inlet subcoolings. This model successfully captures the small variations due to the change of experimental conditions including both inlet subcooling and flow velocity and gives satisfactory predictions. It matches the experimental results in both single phase convective heat transfer and subcooled boiling regions, and predicts the location where departure from nucleate boiling occurs based on the bubble coalescence model. The average prediction error, within the nucleate boiling range, is estimated to be less than $20 \%$, as is shown in Fig. 13. For comparison, the results for EX12 without considering bubble interaction is also displayed in Fig. 12, which are significantly higher than the results with bubble interaction considered after the onset of nucleate boiling. 


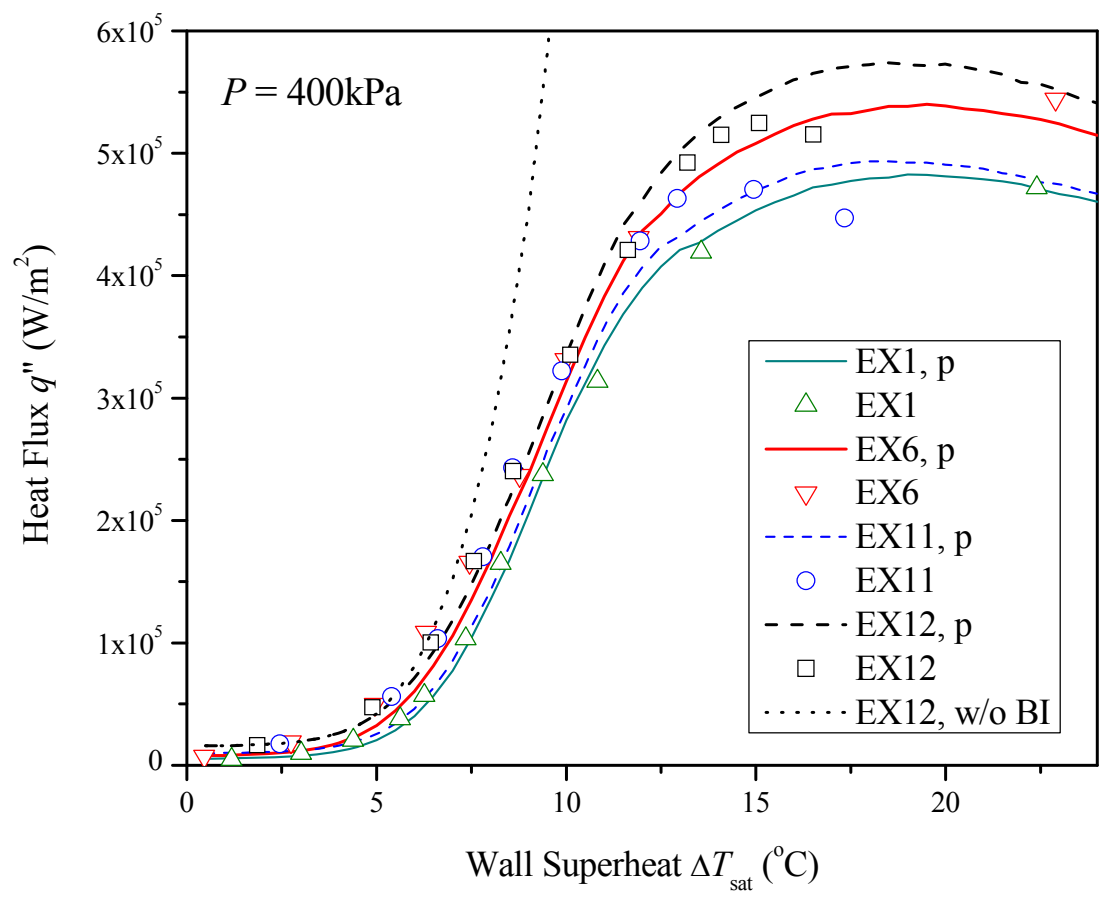

Fig. 12. Boiling Curve Comparison with R134a Data at 400kPa

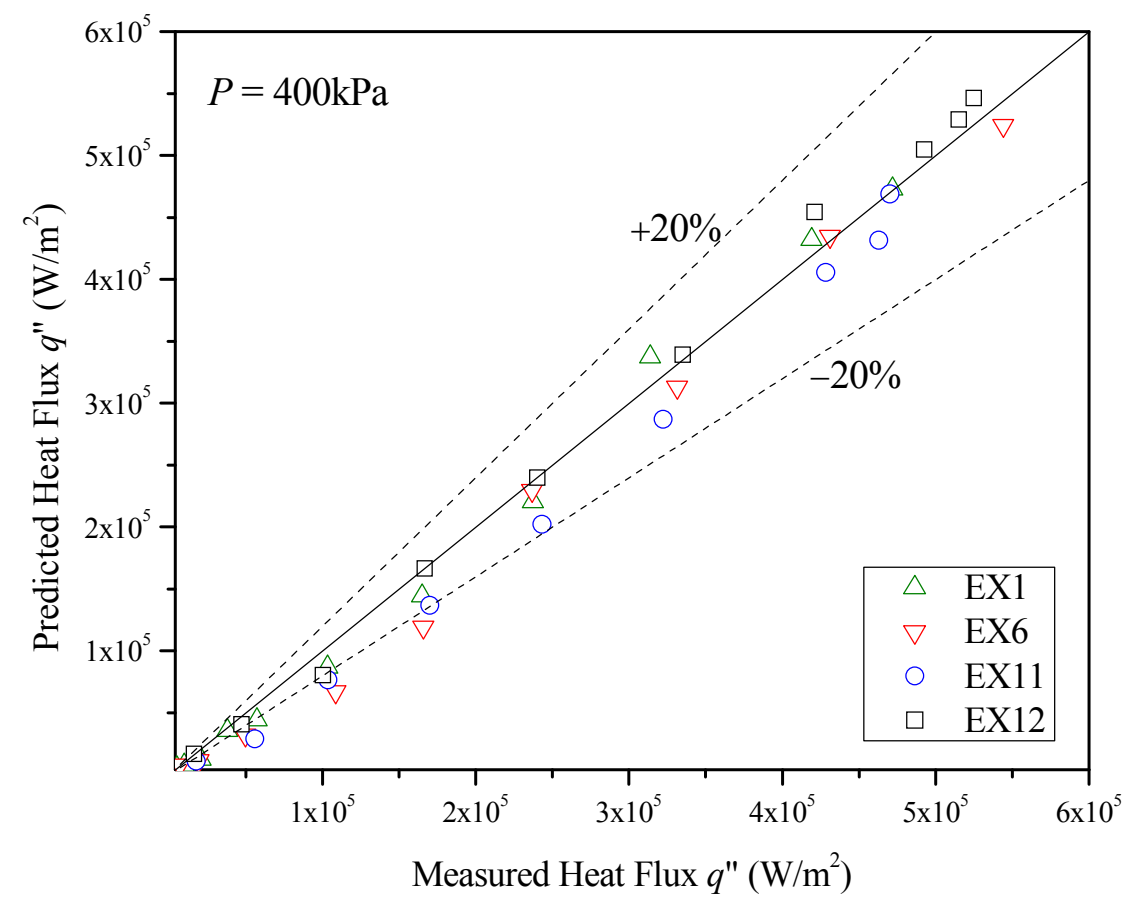

Fig. 13. Heat Flux Comparison at 400kPa 
Fig. 14 shows the predicted variation of bubble lift-off radius distribution under different wall superheats. The bubble departure radii $\left(r_{\mathrm{d}}\right)$ under these conditions are also provided. Bubble interaction increases with increased wall temperature. At $\Delta T_{\text {sat }}=10^{\circ} \mathrm{C}$, bubble population on the heated surface has been sufficiently high so that, as a result of bubble interactions, only $15.1 \%$ of bubbles survive to their maximum sizes and maximizes their contribution to the total heat flux. With a further increase of wall superheat, at $\Delta T_{\text {sat }}=20^{\circ} \mathrm{C}$, bubbles are most likely to interact with others and leave the heated surface at $r_{\mathrm{b}}=22.2 \mu \mathrm{m}$. As a comparison, the bubble force balance model gives $r_{\mathrm{d}}=$ $40.9 \mu \mathrm{m}$, and $r_{1}=172.9 \mu \mathrm{m}$, indicating that most of the bubbles interact and lift-off before they start sliding on the heated surface.

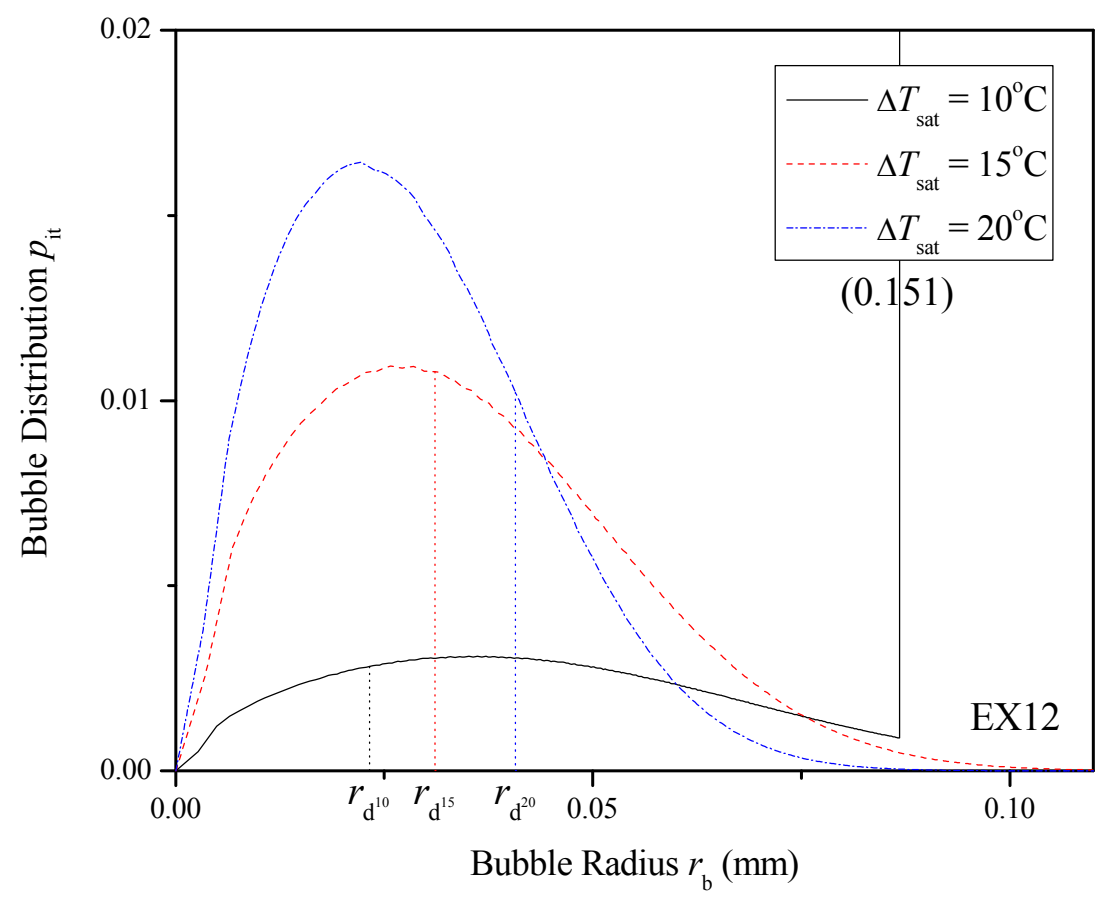

Fig. 14. Bubble Lift-off Radius Distribution at $400 \mathrm{kPa}$

Fig. 15 shows the fractional contributions of various heat transfer mechanisms from model predictions. Heat flux components due to different mechanisms, i.e., $q_{\mathrm{me}}$ (microlayer evaporation), $q_{\mathrm{tc}}$ (transient conduction due to stationary bubbles), $q_{\mathrm{tcs}}$ (transient conduction due to sliding bubbles), and $q_{\mathrm{fc}}$ (forced convection), are traced and reported. At low wall superheats, heat transfer is dominated by single phase forced convection, considering that very few bubbles are generated on the heated surface. With an increase of wall superheat, contributions from both microlayer evaporation and transient conduction, due to sliding bubbles, increase dramatically. This is contributed to 
by the rapid increase in number of bubbles existing on the heated surface. It is noticed that, because the average separation distance of the nucleation sites is much larger than both bubble departure and bubble lift-off radii, bubbles are sparsely displaced on the heated surface. Therefore, most bubbles slide from their originating nucleation sites and lift-off somewhere downstream. The contribution of transient conduction from stationary bubbles (those bubbles that do not slide due to interaction with other bubbles and bulk fluid flow) remains nearly zero. With a further increase of the wall superheat, $q_{\mathrm{me}}$ remains at $60-70 \%$ of the total heat flux, while $q_{\mathrm{tc}}$ increases and $q_{\mathrm{tcs}}$ decreases due to the increased bubble frequency and bubble sizes. Bubble interaction probability increases and results in increased numbers of stationary bubbles and decreased numbers of sliding bubbles. At predicted CHF, the total contribution of transient conduction is around $35 \%$ of the total heat flux with the remaining $65 \%$ is being contributed by microlayer evaporation.

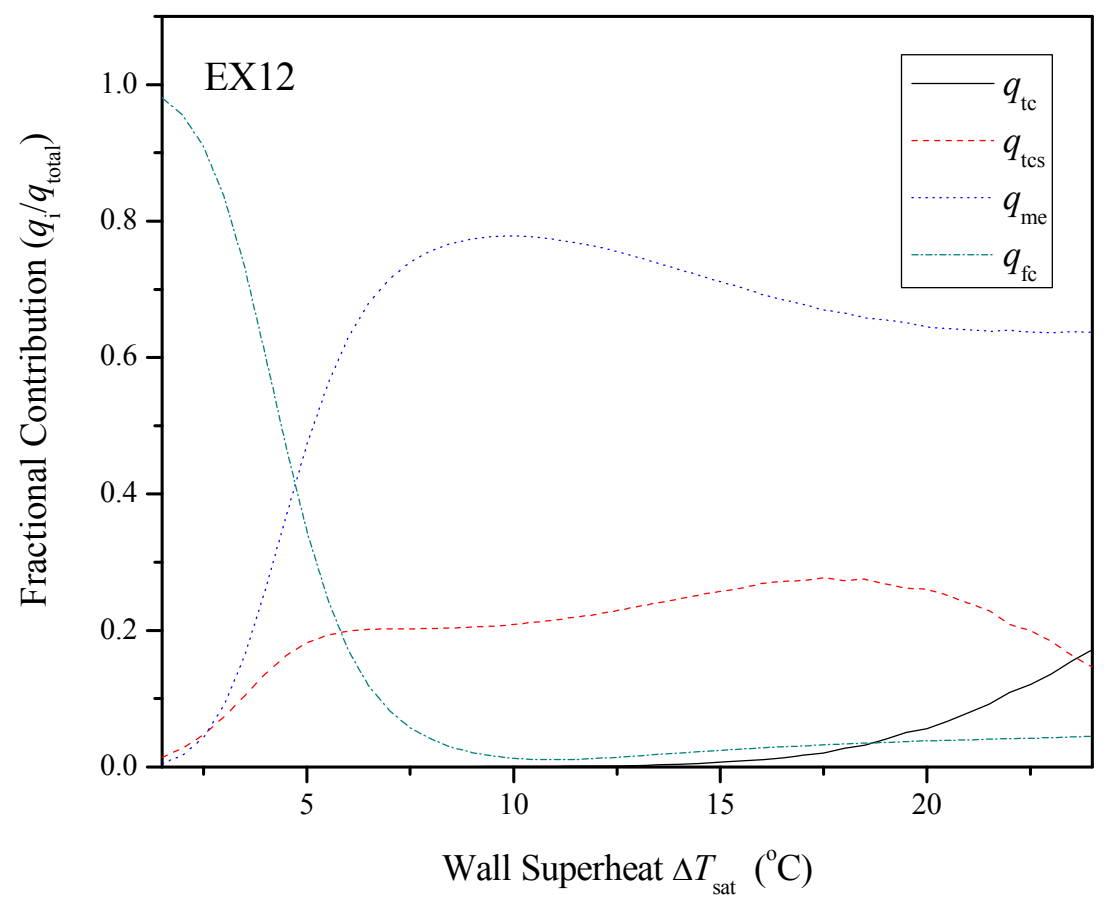

Fig. 15. Fractional Contribution of Heat Flux at 400kPa

\subsubsection{Model Prediction at Higher Pressures}

The comparison of model predictions and experimental results at higher pressures is shown in Fig. 16 to Fig. 21. This model gives best predictions at $400 \mathrm{kPa}$ and $600 \mathrm{kPa}$, while at $800 \mathrm{kPa}$ the average error between the predictions and experimental measurements slightly increases. At $1000 \mathrm{kPa}$ although the predictions are still within $\pm 25 \%$ of the experimental measurements, the difference of slope in the range of the 
subcooled nucleate boiling indicates that this model, being developed and verified at low pressures, may not be fully applicable at high pressures.

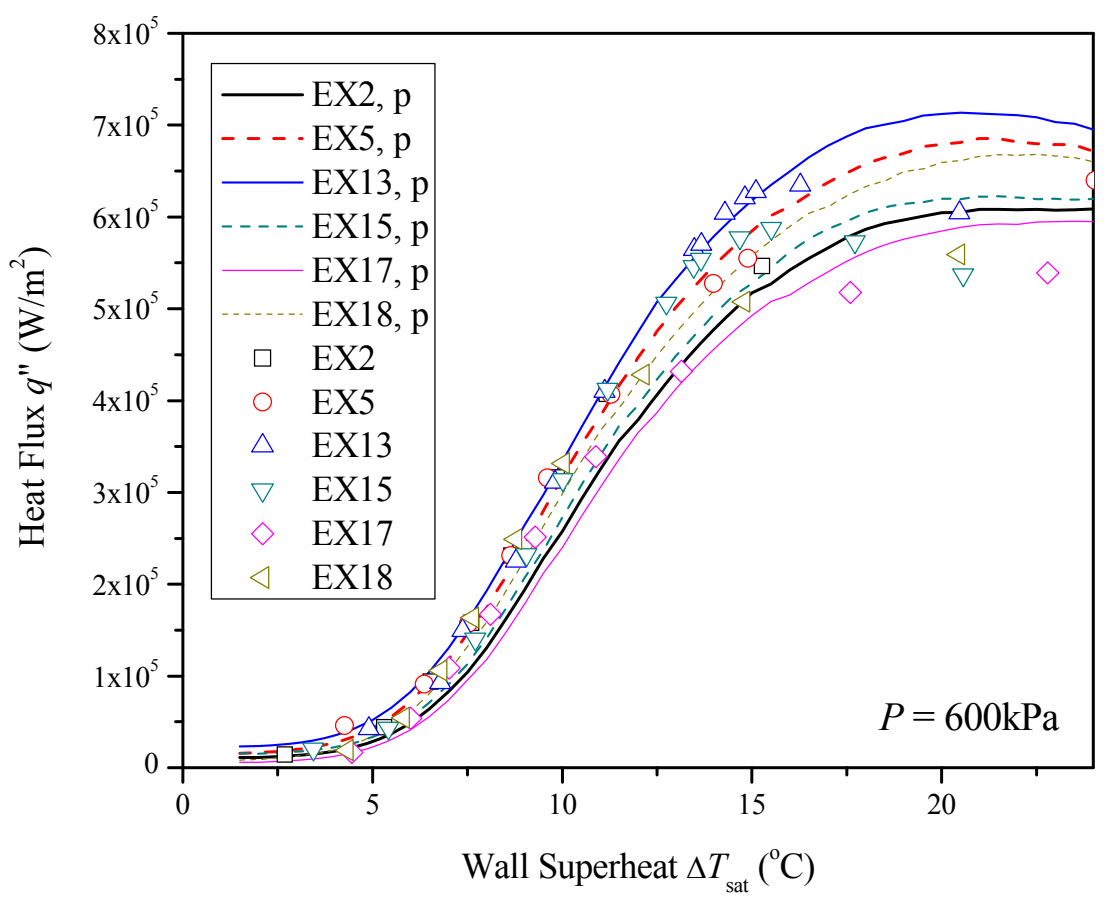

Fig. 16. Boiling Curve Comparison with R134a Data at $600 \mathrm{kPa}$ 


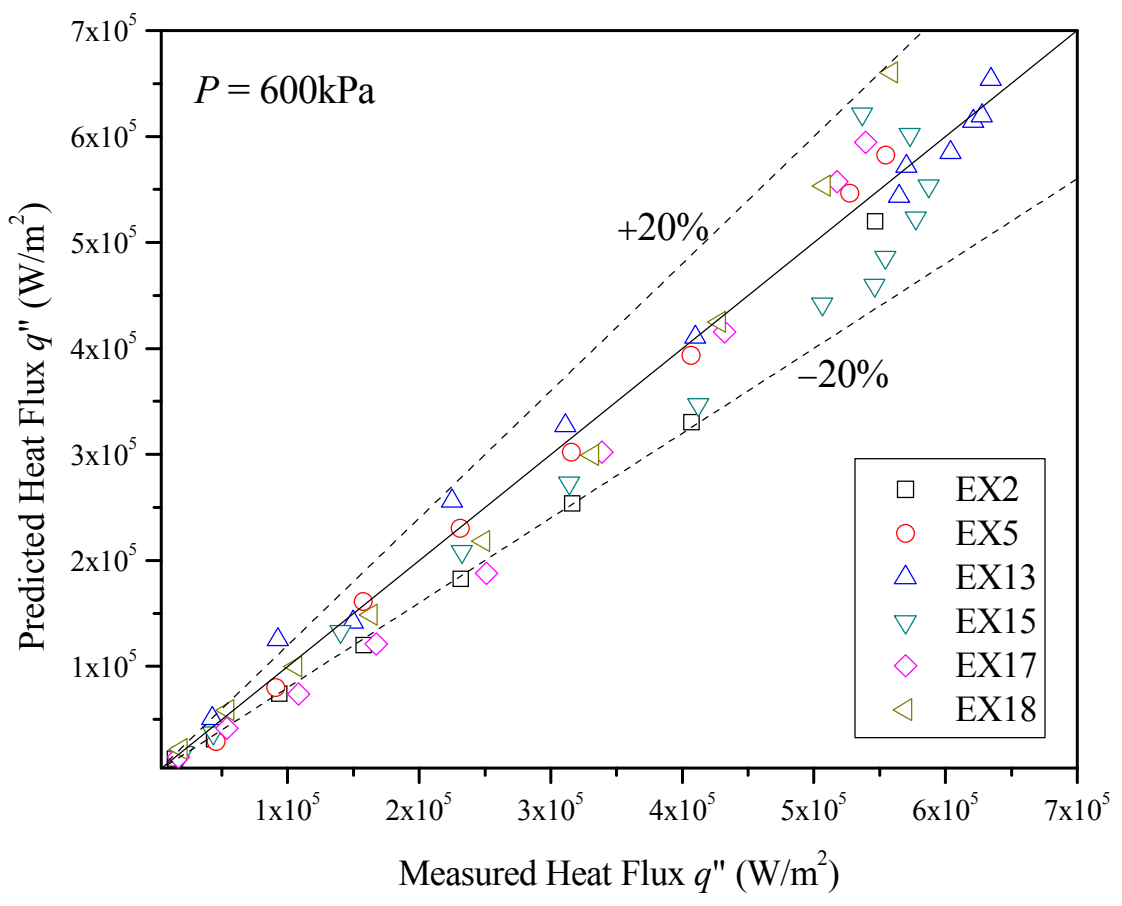

Fig. 17. Heat Flux Comparison at $600 \mathrm{kPa}$

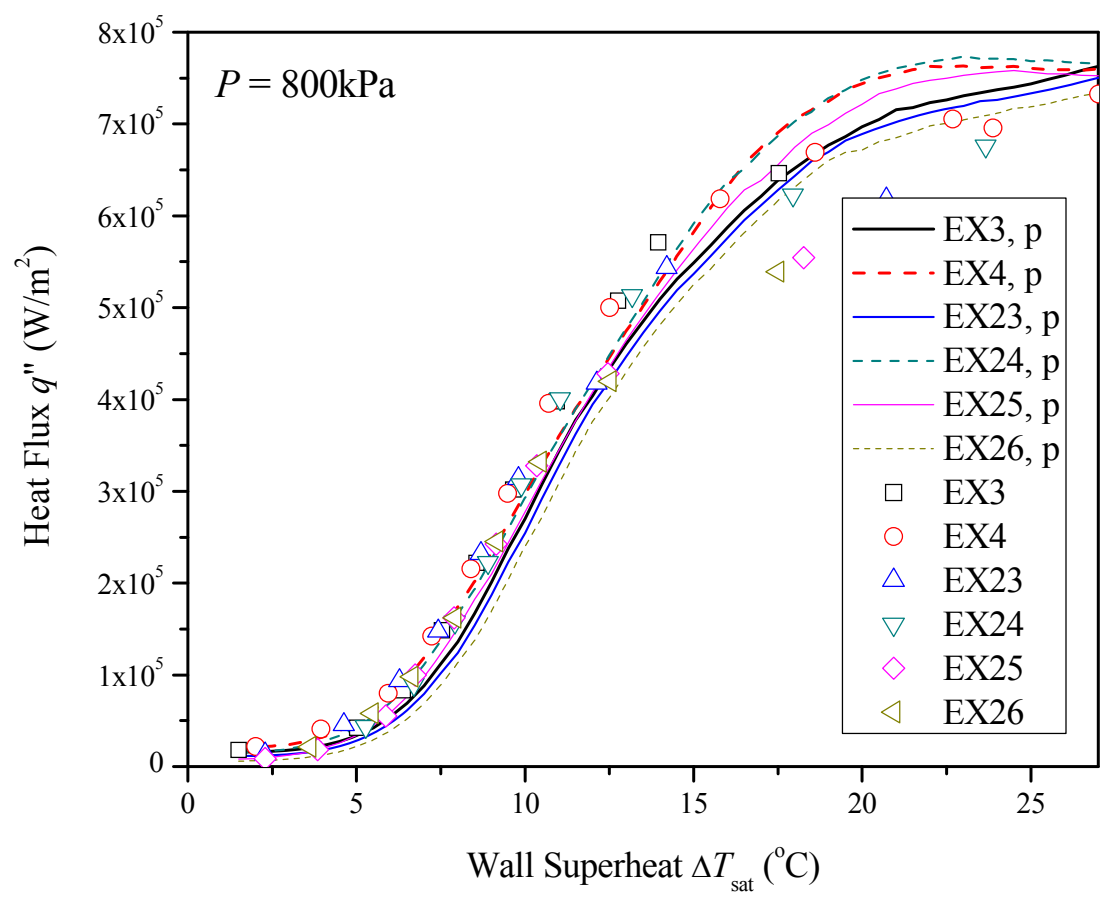

Fig. 18. Boiling Curve Comparison with R134a Data at 800kPa 


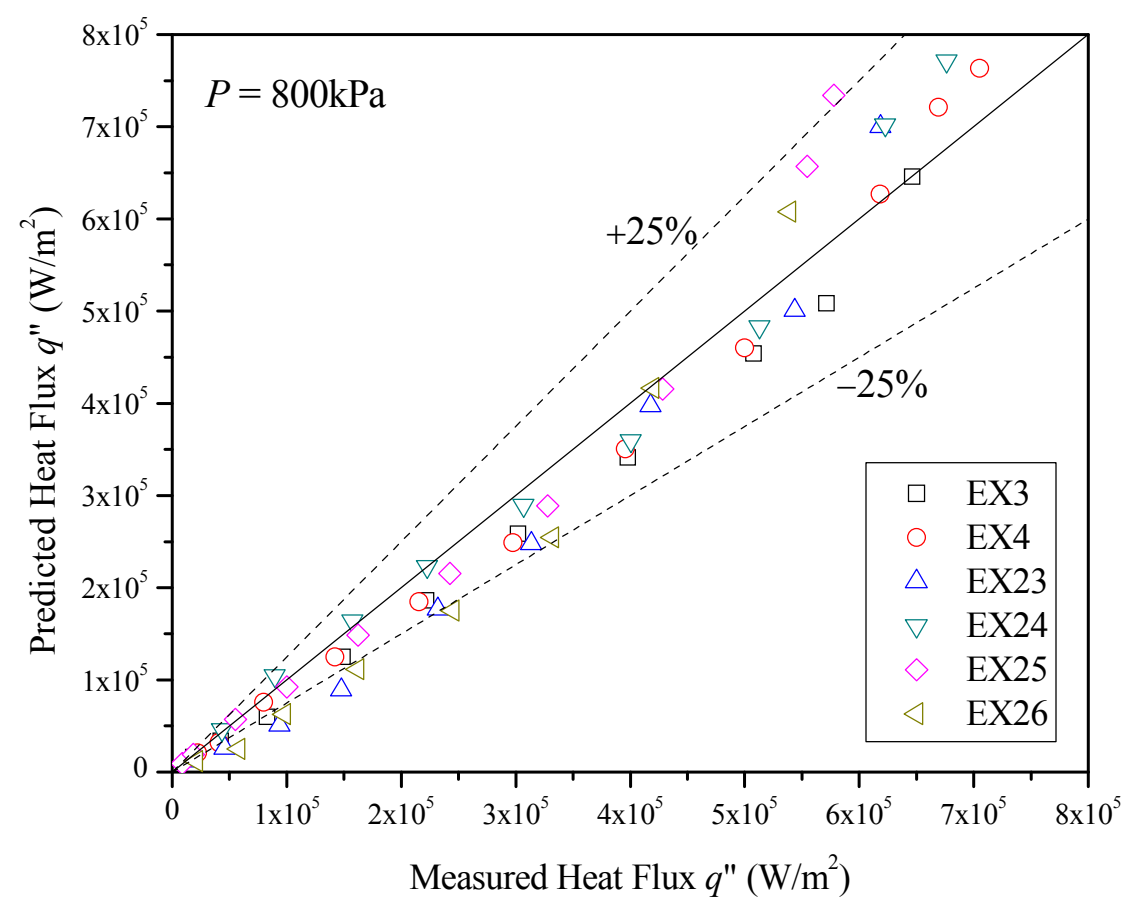

Fig. 19. Heat Flux Comparison at $800 \mathrm{kPa}$

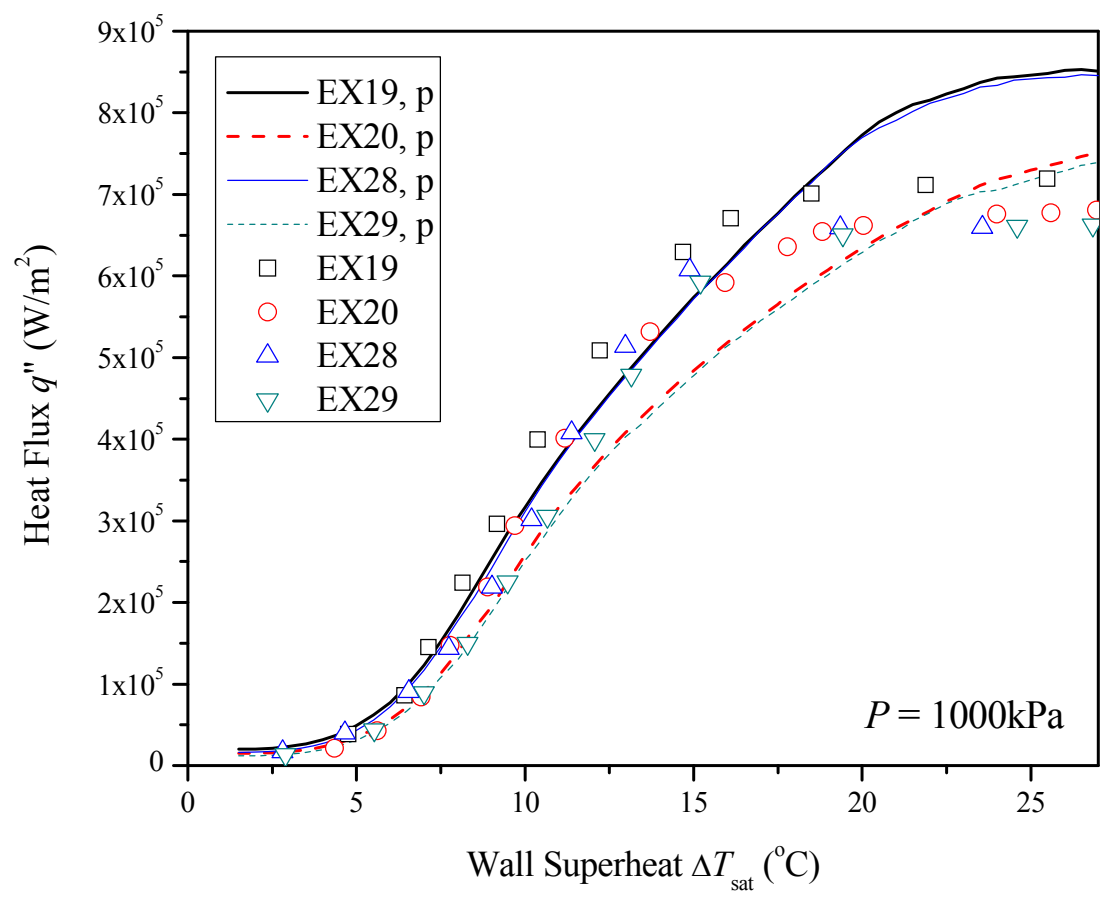

Fig. 20. Boiling Curve Comparison with R134a Data at 1000kPa 


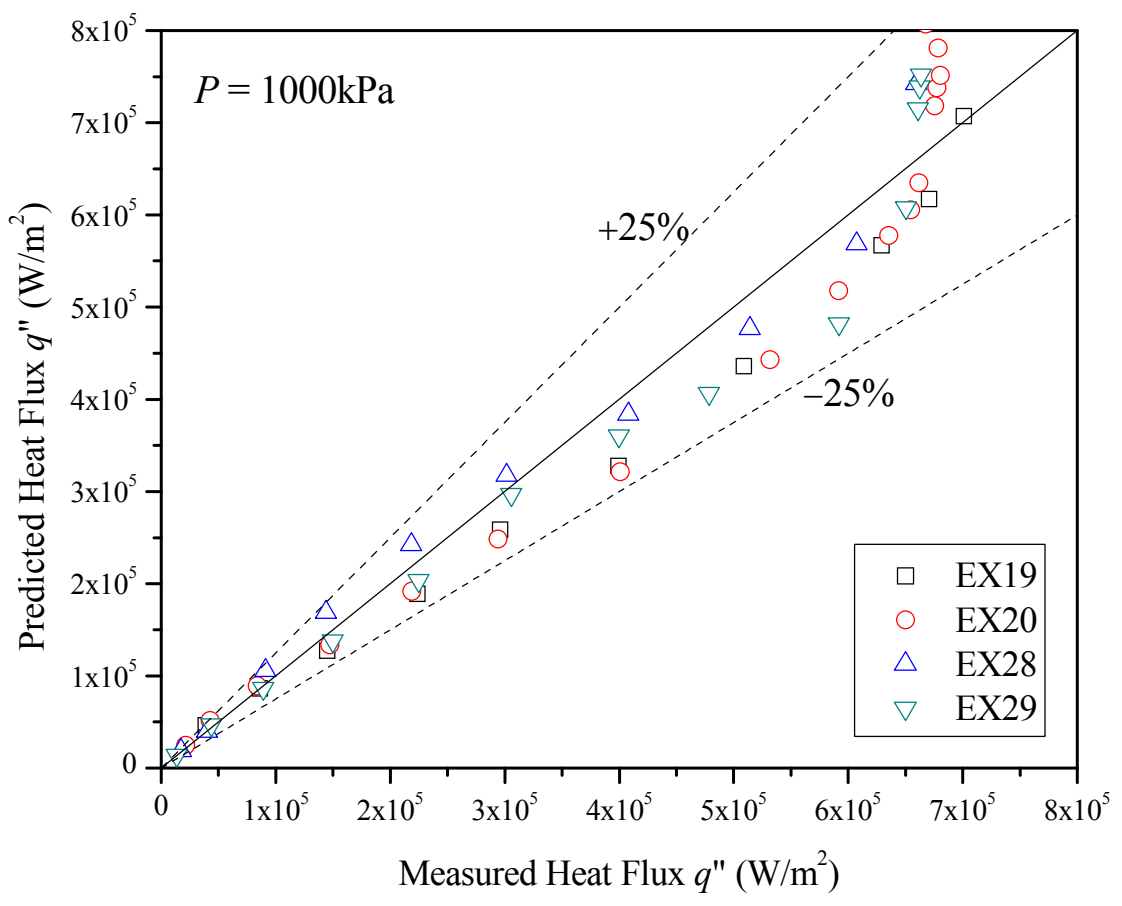

Fig. 21. Heat Flux Comparison at 1000kPa

\subsubsection{Comparison of Critical Heat Flux}

As introduced in a previous section, the prediction of critical heat flux, which characterizes the maximum heat transfer capacity of a heated surface with increased wall superheat, is a natural extension of the prediction of the boiling curve in the model developed in this work. Fig. 22 shows the comparison between the model prediction and the experimental measurements for twenty sets of data collected from $400 \mathrm{kPa}$ to $1000 \mathrm{kPa}$, within which eighteen of them lie in the range of $\pm 20 \%$ of the prediction. This is regarded as a remarkable success for two reasons. First, there have not yet been any models available that give a purely mechanism based prediction of the boiling curve for The subcooled nucleate boiling; and second, none of the models available are capable of predicting the maximum capacity of the heated surface, i.e., critical heat flux, as a natural extension of its prediction of heat flux on a given heat surface. Indeed, although there have been hundreds of correlations of the experimental results, no mechanism based prediction of $\mathrm{CHF}$ is yet available in literature. 


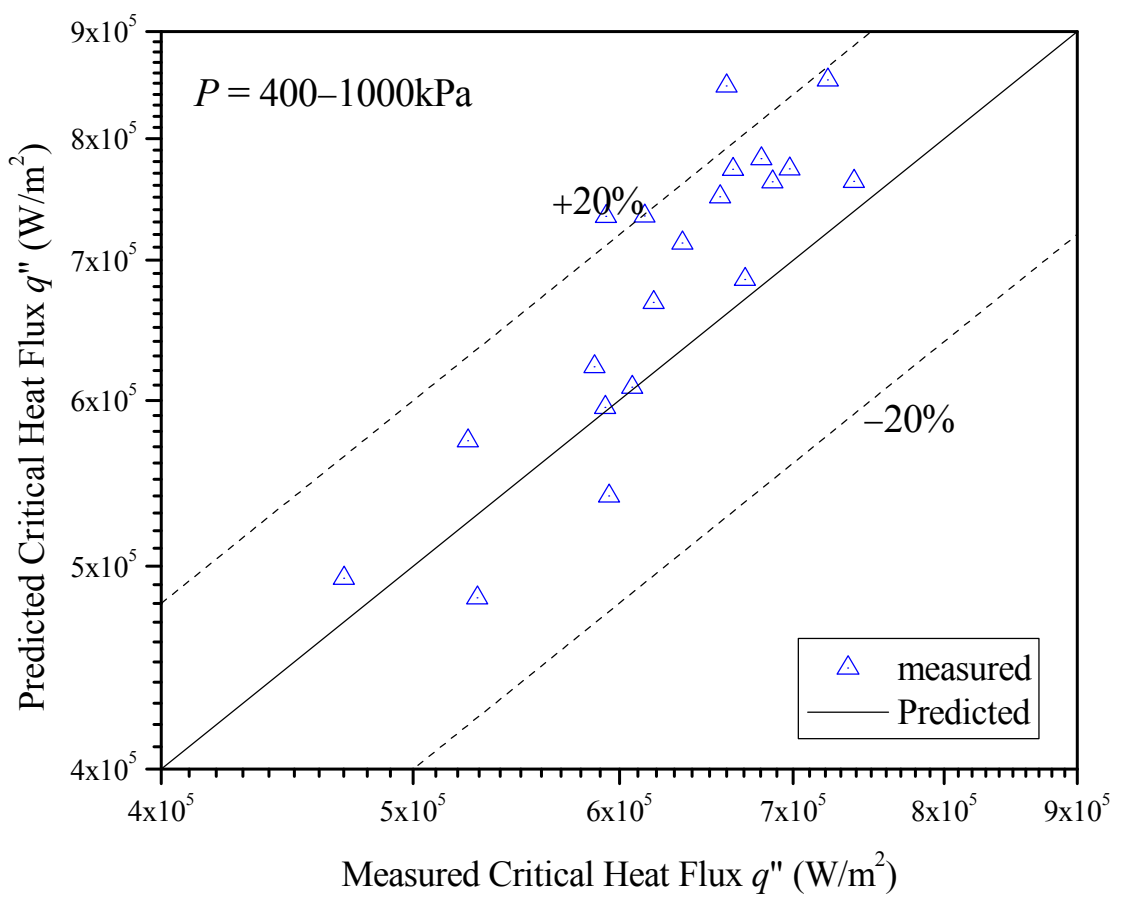

Fig. 22. Critical Heat Flux Comparison with R134a Data

\subsubsection{Comparison to Water Data in the Literature}

The model proposed in section 3 has also been applied to some of the data available in the literature. Fig. 23 and Fig. 24 show comparisons between the experimental data published by McAdams [9] and the predicted boiling curves. Experiments were conducted for water boiling on a vertical stainless steel surface. The conditions were the following: $P=0.413 \mathrm{MPa}, V=1.22 \mathrm{~m} / \mathrm{s}$ (Fig. 23) or $0.34 \mathrm{~m} / \mathrm{s}$ (Fig. 24), $\Delta T_{\text {sat }}=27.8^{\circ} \mathrm{C}$. Since the value of the static contact angle was not measured in their experiments, a typical value of $38^{\circ}$ provided by Basu et al. [10] is used in the calculation. Comparison is done within the range of the experimental data with a good agreement displayed, in both the prediction of the heat flux and the trend of departure from nucleate boiling (for $V=1.22 \mathrm{~m} / \mathrm{s}$ ), as is shown in Fig. 23. Modeling approaches were also made by Basu et al. [10] and Kandlikar [11], but none of them can predict the DNB. This model gives the best mechanistic prediction to date. 


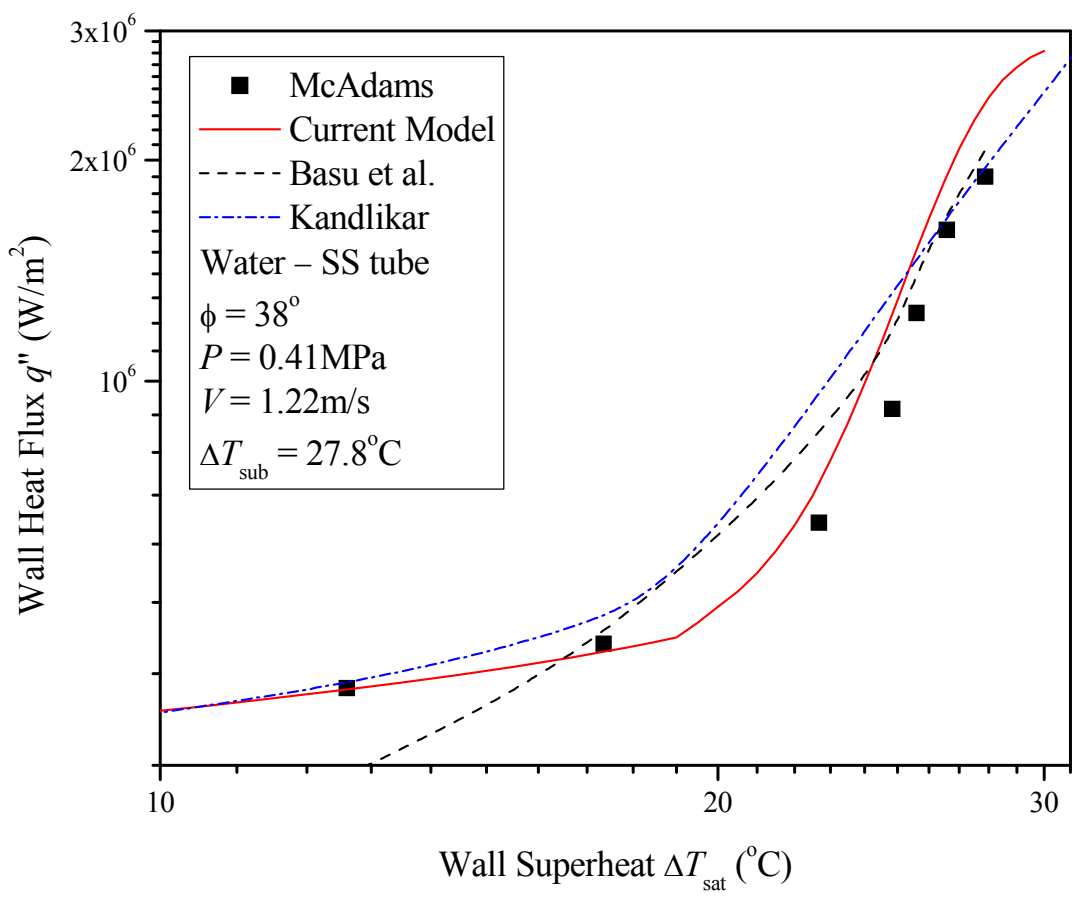

Fig. 23. Boiling Curve Comparison with McAdams' [9] Data

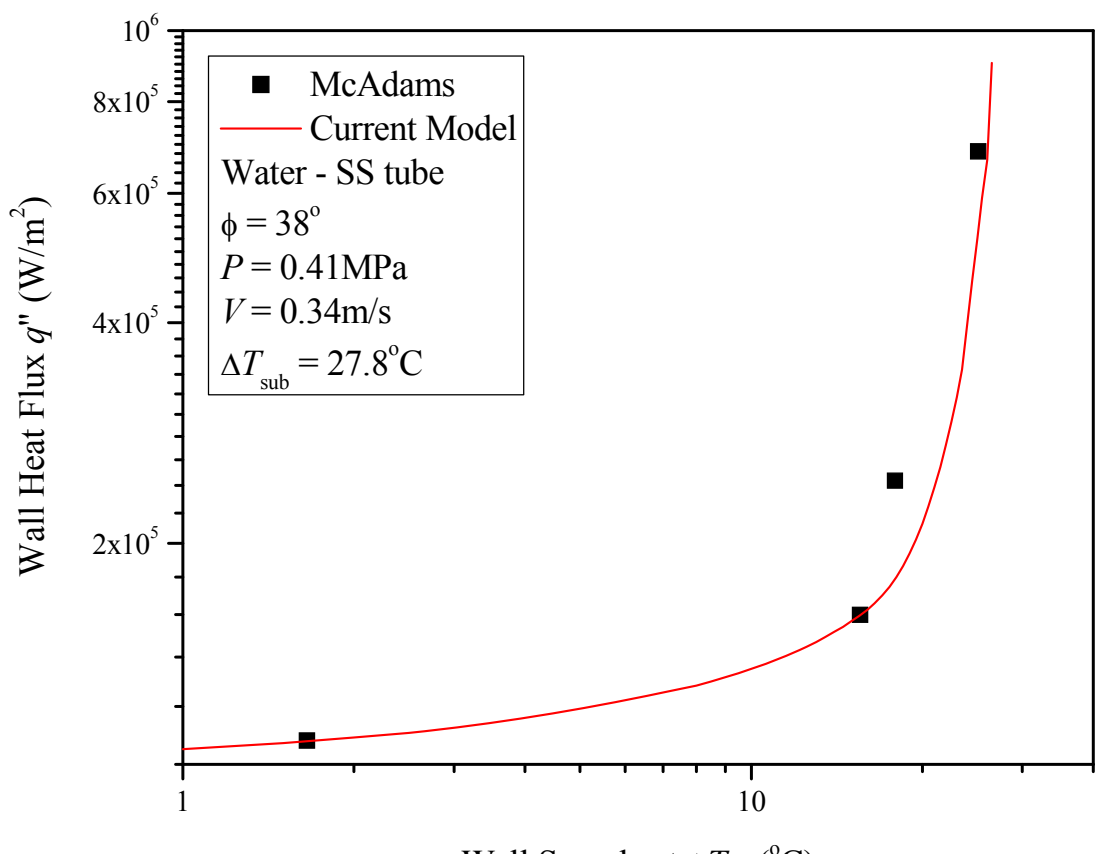

Wall Superheat $\Delta T_{\text {sat }}\left({ }^{\circ} \mathrm{C}\right)$

Fig. 24. Boiling Curve Comparison with McAdams' [9] Data 


\section{Conclusions}

A modeling and experimental study is conduced of the subcooled boiling heat transfer on flat surface. A test facility is designed and constructed to perform required boiling heat transfer experiments. A high-speed visualization system is utilized to give the details of bubble formation and departure and nucleation site density. A unified model of the boiling curve and the critical heat flux is developed through a purely mechanistic approach from the dynamics of bubbles in the flow field. The stochastic nature of bubble motion and bubble coalescence is captured by deriving the probability density function of bubble interaction and developing the bubble lift-off radius distribution.

Experimental data on heat transfer for subcooled flow boiling are obtained for full range of heat flux (terminated at the critical heat flux) and various levels of pressure and subcooling. The investigated flow and condition parameter ranges are: (1) inlet pressure of $400-1000 \mathrm{kPa}$, (2) flow velocity of $0.10-0.25 \mathrm{~m} / \mathrm{s}$, and (3) inlet subcooling temperature of $10-30^{\circ} \mathrm{C}$.

Comparison between the model predictions and the experimental measurements of the boiling curves at $400 \mathrm{kPa}$ shows an average difference of less than $\pm 20 \%$. Small variances of the heat flux resulting from the different inlet subcoolings and flow velocities are successfully captured by the model. Examination of the bubble interaction probability confirms its effect on the boiling curve and the critical heat flux. For boiling in R134a, $60-70 \%$ of the total heat flux is contributed by the microlayer evaporation $\left(q_{\mathrm{me}}\right)$, with the majority of the rest due to the transient conduction.

Predictions are compared with twenty CHF measurements with varying pressures, inlet subcoolings and mass flow rates, with a difference of less than $\pm 20 \%$ observed. The effect of system conditions on CHF is successfully captured. The model prediction is founded to be slightly larger than the experimental results, especially under high system pressure, which can be explained as the local accumulation of vapor bubbles and propagation of surface dryout is not considered in this model.

Validation of this model is not limited to R134a. Predictions are made for water in vertical circular tubes and compared with McAdams [9] data, with good agreement shown. The result also confirms that the application of this model is not limited to horizontal flat heat exchangers. It can be extended to various flow geometries and different flow channel inclinations. In comparison with the similar approaches, e.g., by Basu et al. [10] and Kandlikar [11], a conclusion is tentatively drawn that the prediction given by this purely mechanistic model is superior to these other two models. 


\section{Suggestion}

A model developed in this study successfully explains the existence of critical heat flux and predicts the boiling curve under a range of conditions. Remarkable agreements are achieved in comparing the model with the existing data. Limitation of the model however does exist, i.e., the average prediction error increases with the increase of system pressure. Further investigations are suggested on the effect of system pressure on each sub-model. Improvements are expected on the prediction of activated nucleation sites and the effect of pressure, with the statistical influence of generated bubbles on the activation of nucleation sites considered. A better understanding of the phenomena should lead to further improvement of bubble dynamics and bubble motion modeling in the vicinity of bubble/surface contact and bubble/liquid interface, e.g., the bubble contact angles (the static contact angle, the advancing and receding dynamic contact angles, and the bubble inclination angle, etc.), and the bubble contact area. 


\section{Publications}

1. W. Wu, P. Chen, B. G. Jones, T. A. Newell, "A Study on Bubble Detachment and the Impact of Heated Surface Structure in Subcooled Nucleate Boiling Flows", Nuclear Engineering and Design, 238, 10, 2008, 2693-2698

2. W. Wu, P. Chen, Ty A. Newell, and B. G. Jones, "On The Influence of Heat Surface Structure on Bubble Detachment in Sub-cooled Nucleate Boiling Flows", ICONE14-89546, 2006

3. W. Wu, P. Chen, Ty A. Newell, and B. G. Jones, "Visualization of Sub-Cooled Flow Film Boiling in Horizontal Channel on Flat Heat Exchangers", ICONE14-89548, 2006 


\section{References}

1. W. Wu, "Combined Modeling and Experimental Validation of Boiling Curve and Critical Feat Flux", University of Illinois at Urbana-Champaign, Ph.D. Thesis, 2007

2. G. E. Thorncroft, J. F. Klausner, and R. Mei, "Bubble Forces and Detachment Models", Multiphase Science and Technology, 13, 3\&4, 35-76, 2001

3. F. W. Dittus, L. M. K. Boelter, "Heat Transfer in Automobile Radiators of the Tubular Type," Publications in Engineering, Vol. 2, p. 443, University of California, Berkeley, 1930

4. C. E. Brennen, "A Review of Added Mass and Fluid Inertial Forces", Naval Civil Engineering Laboratory, Port Hueneme, CA, Report CR82.010

5. R. L. Judd, K. S., Hwang, "A Comprehensive Model for Nucleate Boiling Heat Transfer Including Microlayer Evaporation”, J. Heat Transfer, 98, 623-629, 1976

6. G. Sateesh, K. D. Sarit, A. R. Balakrishnan, "Analysis of Pool Boiling Heat Transfer: Effect of Bubbles Sliding on the Heating Surface", Int. J. Heat Mass Transfer, 48, 1543-1553, 2005

7. N. Basu, G. R. Warrier, V. K. Dhir, "Wall Heat Flux Partitioning During Subcooled Flow Boiling: Part I - Model Development”, J. Heat Transfer, 127, 131-140, 2005

8. N. Basu, G. R. Warrier, V. K. Dhir, "Onset of Nucleate Boiling and Active Nucleation Site Density During Subcooled Flow Boiling”, J. Heat Transfer, 124, 717-728, 2002

9. W. H. McAdams, W. E. Kennel, C. S. Minden, Rudolf Carl, P. M. Picornell, and J. E. Dew, "Heat Transfer at High Rates to Water with Surface Boiling", Industrial \& Engineering Chemistry, 41 (9), 1945-1953.

10. N. Basu, G. R. Warrier, V. K. Dhir, "Wall Heat Flux Partitioning During Subcooled Flow Boiling: Part II - Model Validation”, J. Heat Transfer, 127, 141-148, 2005

11. S. G. Kandlikar, "Further Developments in Subcooled Flow Boiling Heat Transfer", Engineering Foundation Conference on Convective and Pool Boiling, Irsee, Germany, May 18-25, 1997 